NBER WORKING PAPER SERIES

\title{
TESTING MACROPRUDENTIAL STRESS TESTS: THE RISK OF REGULATORY RISK WEIGHTS
}

\author{
Viral V. Acharya \\ Robert Engle \\ Diane Pierret \\ Working Paper 18968 \\ http://www.nber.org/papers/w18968
NATIONAL BUREAU OF ECONOMIC RESEARCH 1050 Massachusetts Avenue
Cambridge, MA 02138
April 2013

The authors thank supporters of the Volatility Institute of the Stern School at NYU for financial support that made this research possible. Thanks go to the Sloan Foundation, the Banque de France, the University of New South Wales, the Universite de Lausanne, Deutsche Bank, Blackrock and the Michael Armellino Foundation. The views expressed herein are those of the authors and do not necessarily reflect the views of the National Bureau of Economic Research.

NBER working papers are circulated for discussion and comment purposes. They have not been peerreviewed or been subject to the review by the NBER Board of Directors that accompanies official NBER publications.

(C) 2013 by Viral V. Acharya, Robert Engle, and Diane Pierret. All rights reserved. Short sections of text, not to exceed two paragraphs, may be quoted without explicit permission provided that full credit, including $(\odot$ notice, is given to the source. 
Testing Macroprudential Stress Tests: The Risk of Regulatory Risk Weights

Viral V. Acharya, Robert Engle, and Diane Pierret

NBER Working Paper No. 18968

April 2013

JEL No. G01,G11,G21,G28

\begin{abstract}
$\underline{\text { ABSTRACT }}$
Macroprudential stress tests have been employed by regulators in the United States and Europe to assess and address the solvency condition of financial firms in adverse macroeconomic scenarios. We provide a test of these stress tests by comparing their risk assessments and outcomes to those from a simple methodology that relies on publicly available market data and forecasts the capital shortfall of financial firms in severe market-wide downturns. We find that: (i) The losses projected on financial firm balance-sheets compare well between actual stress tests and the market-data based assessments, and both relate well to actual realized losses in case of future stress to the economy; (ii) In striking contrast, the required capitalization of financial firms in stress tests is found to be rather low, and inadequate ex post, compared to that implied by market data; (iii) This discrepancy arises due to the reliance on regulatory risk weights in determining required levels of capital once stress-test losses are taken into account. In particular, the continued reliance on regulatory risk weights in stress tests appears to have left financial sectors under-capitalized, especially during the European sovereign debt crisis, and likely also provided perverse incentives to build up exposures to low risk-weight assets.
\end{abstract}

Viral V. Acharya

Stern School of Business

New York University

44 West 4th Street, Suite 9-84

New York, NY 10012

and CEPR

and also NBER

vacharya@stern.nyu.edu

Robert Engle

Department of Finance, Stern School of Business

New York University, Salomon Center

44 West 4th Street, Suite 9-160

New York, NY 10012-1126

and NBER

rengle@stern.nyu.edu

\author{
Diane Pierret \\ Volatility Institute, Stern School of Business \\ New York University \\ 44 West 4th Street, KMC 9-66 \\ New York, NY 10012 \\ dpierret@stern.nyu.edu
}




\section{Introduction}

Since the financial crisis of 2008, macroprudential stress tests have become a standard tool used by regulators to assess the resilience of financial systems. Macro stress tests have been designed to help macroprudential regulation, which essentially aims at preventing the costs of financial distress to spread to the real economy (Acharya et al. (2009, 2010a,b, 2012); Borio and Drehmann (2009); Hanson et al. (2011); Hirtle et al. (2009)). Therefore, macro stress tests focus on a group of financial institutions that, taken together, can have an impact on the economy (Borio et al. (2012)) and create systemic risk. Macroprudential regulation of these institutions reduces the probability and the cost of a financial crisis by forcing institutions to internalize their contribution to systemic risk.

However, concerns have been raised that macro stress tests do not serve the goal of macroprudential regulation as they should. Greenlaw et al. (2012) argue that macro stress tests are still microprudential in nature since they focus on the solvency of individual institutions. They also remain microprudential as they fail to characterize the 'endogenous' nature of systemic risk (Borio and Drehmann (2009); Galati and Moessner (2011)). According to Borio and Drehmann (2009), macro stress tests "risk lulling policymakers in a false sense of security" as they fail to provide real-time ex ante measurement of systemic risk.

Macro stress tests are also strongly dependent on Basel regulation defining measures (the capital ratios) of the financial performance of banks. Hanson et al. (2011) show that the capital ratios give incentives to banks to shrink their assets, which in turn leads to the amplification of financial distress. More recent concerns focus on the denominator of capital ratios (the risk-weighted assets) where the Basel Committee on Banking Supervision (2013) recognizes in a recent survey the inconsistency of risk weights measurement across banks. Haldane $(2011,2012)$ also raises fears over the complexity and the robustness of risk weights and calls for simpler market-based metrics.

In this paper, we test macroprudential stress tests (including the most recent ones) by comparing their outcomes to those from a simple methodology that relies on publicly available market data (see Acharya et al. (2010a,b, 2012); Brownlees and Engle (2011)). ${ }^{1}$ The proposed measure (SRISK) represents the capital shortfall a financial institution would need to raise during a crisis, and is available on the NYU Volatility Laboratory website (Vlab). ${ }^{2}$ Vlab methodology is viewed in this paper as a benchmark to macro stress tests that addresses

\footnotetext{
${ }^{1}$ Other surveys on macroprudential stress tests include Alfaro and Drehmann (2009); Borio et al. (2012); Greenlaw et al. (2012); Hirtle et al. (2009); Schuermann (2012).

${ }^{2}$ http://Vlab.stern.nyu.edu/
} 
many of the above concerns.

The test of macroprudential stress tests comprises three steps, namely: (i) We compare projected losses from stress tests to market-implied losses and actual realized losses; (ii) We compare required capital shortfalls of stress tests to the market-implied capital shortfall SRISK; and (iii) we consider the efficacy of regulatory risk weights and outline incentives created by the reliance on risk weights in asset portfolio decisions of banks.

Our assessment of regulatory stress tests reveals that the projected losses of stress tests and Vlab correlate well and both predict well the actual realized losses of banks under severe economic conditions. In striking contrast, the required capitalization of financial firms in stress tests is found to be rather low, and inadequate ex post, compared to SRISK. We document that this discrepancy arises due to the reliance on regulatory risk weights in determining required levels of capital once stress-test losses are taken into account.

The deviation with Vlab is even greater when the impact of the stress scenario is translated into higher risk weights (as in European stress tests) since the stressed risk weights are uncorrelated to the actual risk of banks during a crisis. Furthermore, Basel risk standards are proven to provide no incentives for banks to diversify as risk weights ignore the subadditivity feature of portfolio risk. Therefore, firms tend to concentrate their entire portfolio on one asset category or exposure according to a false risk weight, and the underestimation of risk weights (as banks use their own models in Basel II) automatically leads to excess leverage.

This reliance on regulatory risk weights appears to have not only left financial sectors under-capitalized (especially during the European sovereign debt crisis), but likely also provided perverse incentives to build up exposures to low risk-weight assets. Overall, we argue that stress tests relying on Basel risk regulation are not sufficient because (a) the increase of risk over time cannot be captured ex ante without market-based measures, and (b) risk weights are flawed cross-sectionally as banks can game their risk-weighted assets, i.e. take advantage of (a) to reduce their regulatory capital requirements. Without using market measures of risk, a capital requirement based on the size and leverage of banks delivers more consistent results than the risk-based capital shortfall of stress tests.

The rest of the paper is structured as follows: Section 2 introduces macroprudential stress tests and Vlab. We test the stressed losses of stress tests in Section 3 and the stressed capital ratios and shortfalls in Section 4. The efficacy of regulatory risk weights is tested in Section 5. 


\section{Stress tests and Vlab}

\subsection{Macroprudential stress tests sample}

We consider stress tests conducted on a US and EU-wide level. These stress tests can be qualified as macroprudential stress tests as opposed to microprudential stress tests conducted on a bank-level as a requirement under the Pillar II of Basel II (Internal Capital Adequacy Assessment Process (ICAAP)). Other macroprudential stress tests, not discussed here, were undertaken by national authorities (e.g. Ireland, UK, Spain) and by the International Monetary Fund.

The Board of Governors of the Federal Reserve has been responsible for conducting macroprudential stress tests in the US. A first stress test exercise called the Supervisory Capital Assessment Program (SCAP) was launched in 2009 as a response to the 2008 financial crisis. With the Dodd-Frank Act of 2010, an annual supervisory stress test of the US financial system became a requirement, and the Fed's capital plans rule of 2011 required all US bank holding companies with consolidated assets of $\$ 50$ billion or more to develop and submit capital plans to the Federal Reserve on an annual basis. As a result, the Federal Reserve conducted stress tests as part of the Comprehensive Capital Analysis and Review (CCAR) in 2011, 2012 and 2013.

EU-wide stress tests were initiated by the Committee of European Banking Supervisors (CEBS) in 2009 and 2010. The CEBS became the European Banking Authority (EBA) on January 1, 2011, which coordinated a new stress test the same year. As opposed to US stress tests by the Federal Reserve, European stress tests are conducted in a bottom-up fashion: banks submit their stress test results to national supervisory authorities (NSAs) for review before NSAs submit to the EBA. For this reason, the EBA qualifies the EU-wide stress test exercise as a microprudential stress test. These stress tests are however the outcome of a global macroeconomic scenario defined by the European Central Bank (ECB) and share the objective of an overall assessment of systemic risk in the EU financial system.

Stress tests can have different goals depending on their context: the SCAP 2009 is a good example of a crisis management tool as opposed to pre-emptive, forward-looking stress tests that followed. The EBA 2011 disclosed in July 2011 also served as a confidence-building tool during the European sovereign debt crisis. The EBA Capital Exercise released in December 2011 is not a stress test but has been an additional tool to restore market confidence with the recommendation and the creation of an exceptional and temporary capital buffer.

The disclosure level of a stress test outcome is a very strategic decision of the regulator that is well discussed in Goldstein and Sapra (2012), Petrella and Resti (2013) and Schuer- 
mann (2012). Some stress tests only disclose the stress scenario; other stress tests disclose an aggregate outcome of the stress scenario. On the opposite, the EBA 2011 stress test has an unprecedented level of transparency for the EU banking system. The amount of information at the bank level is very high and downloadable in an excel file from the EBA website. ${ }^{3}$ To our knowledge, only three US and two EU-wide macroprudential stress tests publicly disclosed a bank-level outcome of the stress test exercise; the SCAP 2009, the CCAR 2012 and the CCAR 2013 in the US; the CEBS 2010 and the EBA 2011 in the European Union. These five macroprudential stress tests with bank level disclosure are the sample of stress tests of this paper. Their outcomes and the outcome of the EBA Capital Exercise are summarized in Tables 1 (US) and 2 (EU).

\subsection{An alternative to stress tests: Vlab}

Next to stress tests conducted by US and European regulators, a team of researchers at NYU Stern School of Business developed an alternative methodology to measure the systemic risk of financial institutions purely based on publicly available information (see Acharya et al. (2010a, 2012); Brownlees and Engle (2011)). The results of this methodology are available on the Volatility Laboratory website (Vlab), where systemic risk rankings are updated weekly both globally and in the United States (see http://Vlab.stern.nyu.edu/). The systemic risk measure (SRISK) of Vlab represents the capital an institution would need to raise in the event of a crisis. SRISK of a financial institution depends on its size, its leverage and its stock return during a crisis (Long-Run Marginal Expected Shortfall), where the crisis is defined by a $40 \%$ fall in aggregate market equity over a six-month time window.

The Long-Run Marginal Expected Shortfall (LRMES) captures the co-movement of a firm with the market index; LRMES is the average of a firm's returns across the simulation paths where the market return falls by $40 \%$ over six months (see Brownlees and Engle (2011)). ${ }^{4}$ Defining $M V$ as today's market capitalization of a firm, LRMES*MV is the expected market cap loss that equity holders would face during the 6-month crisis scenario. The capital shortfall of a firm (SRISK) is then derived assuming the book value of its debt $(D)$ stays unchanged over the six-month scenario while its market cap falls by $L R M E S * M V$

$$
S R I S K=\mathrm{E}[k(D+M V)-M V \mid \text { crisis }]=k D-(1-k)(1-L R M E S) * M V,
$$

\footnotetext{
${ }^{3}$ http://www.eba.europa.eu/EU-wide-stress-testing/2011/2011-EU-wide-stress-test-results.aspx

${ }^{4}$ The equity market return is the S\&P500 for US banks, the MSCI ACWI World ETF index for European banks. Note that for European banks, the long run simulation is not yet implemented and LRMES is approximated by 1-exp(-18*MES) where MES is the expected daily return of the bank if the daily market return is less than $-2 \%$.
} 
where $k$ is the prudential capital ratio.

Vlab uses a prudential capital ratio $k$ of $8 \%$ for US banks and a milder $k$ of $5.5 \%$ for European banks to account for the difference in leverage due to different accounting standards in the two regions: EU banks report under IFRS whereas US banks report under US GAAPs. Under US GAAPs, banks are allowed to report their derivatives on a net basis. The netting of derivatives is most of the time not allowed under IFRS norms leading to a substantial increase of the size of the balance sheet. Engle et al. (2012) indicate that the total assets of large US banks would be between $40 \%$ and $60 \%$ larger under IFRS than under US GAAPs.

As the stress is on the market value of equity, Vlab methodology can be viewed as a markto-market stress test. Vlab does not have the information granularity of the supervisory data of regulatory stress tests but the use of publicly available market data allows for realtime forward looking measures. Moreover, the simplicity of the Vlab scenario compared to the complex multi-factor scenarios of stress tests makes Vlab outcomes robust to various economic environments. Vlab is therefore used as a macroprudential benchmark in the assessment of regulatory stress tests outcomes. Differences in scenarios and data of Vlab and regulatory stress tests are further discussed in Appendix A.

We show the aggregate output of common banks between stress tests and Vlab in Table 3. All the banks in US and EU stress tests are not available in Vlab mainly because some banks in the stress tests samples are not publicly traded. Vlab reports the results of 18 of the 19 US BHCs (all except Ally Financial Inc.) and close to 60\% of the banks in European stress tests.

In the next sections, we test the outcome of stress tests against this market-implied benchmark and banks' real outcomes during the European sovereign debt crisis. We first test the projected losses of stress tests against the market capitalization loss of Vlab and actual realized losses in Section 3. Second, we test the capital requirements implied by stress tests against SRISK in Section 4. This two-step test allows disentangling the effect of different stress scenarios that directly impact projected losses, from the impact of different risk measures. Then, a third test compares the regulatory risk weights of stress tests and the market risk weight of Vlab with realized measures of risk in Section 5 .

\section{Testing stressed losses}

Stress test models translate the stress scenario into a bank outcome. The most direct impact of the stress scenario should be visible on banks' projected losses. We show that, despite different scenarios, data and models, stress tests losses and Vlab losses correlate well, 
and both predict well the ranking of banks realized losses under severe economic conditions.

\subsection{Stress tests vs. Vlab losses}

We compare the projected losses of stress tests with Vlab market cap loss ( $M V * L R M E S)$ in Table 3. From this table, we notice the important gap between the "Loss" and the "Net Loss" of stress tests (especially in Europe) due to the effect of projected revenues under the stress scenario. The net loss is the main driver of capital diminution under stress and is the accounting equivalent of the Vlab loss. However, the order of amplitude of Vlab losses is similar to the amplitude of 'pure' losses of stress tests that do not include the stressed revenues. Moreover, Vlab loss is a six-month loss whereas stress tests losses are projected over two years. Vlab market cap loss therefore appears more severe than the stress tests capital losses.

The rank correlations of Vlab loss with the total losses of stress tests are very high and significant in all stress tests (see Table 4, panel A). Huang et al. (2012) do the same test for the SCAP and find that the stress test losses are well correlated to several market-based measures of systemic risk; ${ }^{5}$ our rank correlation estimate of 0.68 is close to their estimate of 0.67 for the Marginal Expected Shortfall (MES) of Acharya et al. (2010b). ${ }^{6}$ We also report the correlations of Vlab loss with the stress tests loan losses and trading losses since they are the most important sources of losses (85\%) according to the CCAR 2012. The correlations of Vlab loss with the loan and trading losses are also very high and significant, making Vlab ranking and the ranking of losses under supervisory stress scenarios very consistent.

The correlations of Vlab loss with the total net loss (including stressed revenues) are smaller for all stress tests and negative in Europe; banks with higher profits under the EBA and CEBS stress scenarios are predicted to have higher losses in Vlab. Some banks are actually reporting positive profits under the stress scenario of stress tests where modeling assumptions on revenues cover the stressed losses. ${ }^{7}$ The profits are then reported in the

\footnotetext{
${ }^{5}$ The Marginal Expected Shortfall (MES) of Acharya et al. (2010b), the CoVaR of Adrian and Brunnermeier (2010), and the marginal contribution to the Distress Insurance Premium (DIP) of Huang et al. (2009).

${ }^{6}$ With the difference that Huang et al. (2012) use the marginal expected shortfall (MES) instead of the long-run counterpart LRMES, and the MES is multiplied by the Tier 1 capital instead of the market cap.

${ }^{7}$ First, the stress scenario is not an absolute scenario as in Vlab but is defined as a deviation from a baseline scenario. If some banks are projected to make large profits in the baseline scenario, they will make lower but still positive profits under the adverse scenario. Second, the EBA explains that the stress scenario may lead to a higher net interest income where some banks assume that the impact of higher interest rates will be passed onto customers without a corresponding increase in the cost of funding for the bank. Then, the EBA considers a directional market risk stress test; depending on the direction of their exposures banks can realize trading gains on certain portfolios.
} 
balance sheet so that the divergence with Vlab is also visible in capital changes. We show in Figure 1 that the projected profits under the EBA stress scenario lead to increasing capital levels for many banks with the largest Vlab losses.

\subsection{Predicting banks' real losses during the European sovereign debt crisis}

It is important to note that stress tests outcomes are not a usual forecast; it is a forecast conditional on a specific adverse macro-economic scenario. Ideally, we would compare stress tests outcomes to the real outcomes of banks during a period where the state of the world is exactly the same as described in the stress scenario. The exact stress scenario does not occur in reality so we select stress tests followed by a period where the economic conditions sufficiently deteriorate to pretend it is a realization of the stress scenario.

Figure 2 illustrates the disclosure dates of the different stress tests (vertical bars) together with the six-month forward return of three indices: a US (S\&P500), a European (Eurostoxx50) and a global index (MSCI ACWI World). The figure shows that only two stress tests are followed by a global economic downturn: the CCAR 2011 in the US and the EBA 2011 in the EU. The CCAR 2011 was disclosed on March 18, 2011 and the EBA 2011 on July 15, 2011. However, only the EBA 2011 discloses a bank-level output of the stress test exercise. Five months later, the disclosure of the EBA Capital Exercise on December 8, 2011 is followed by a more mixed performance of the economy: the European and world index returns are still slightly negative, but the S\&P500 is positive again.

We focus on the EBA 2011 stress test to assess the forecasting performance of Vlab and stress tests, as it is the only stress test with bank-level disclosure followed by a global economic downturn. The realized returns from 06/30/2011 to 12/31/2011 of the S\&P500, the Eurostoxx50 and the ACWI World index are respectively $-4.89 \%,-20.67 \%$, and $-13.47 \%$. This outcome is less severe than the Vlab scenario ( $40 \%$ decline in the World equity index) and is closer to the ECB scenario (15\% decline in stock prices in the Euro area).

Table 5 shows the similar performance of Vlab and the EBA in forecasting the actual ranking of banks realized outcomes during the European sovereign debt crisis. We consider as realized outcomes the realized loss (panel A) and the realized return (panel B). The realized return of bank $i$ at time $t$ is $-\sum_{t+1}^{t+1+W} \ln \left(p_{i t} / p_{i t-1}\right)$, where $p_{i t}$ is the stock price of the bank and its realized loss is defined by

$$
\text { Realized } \operatorname{loss}_{i, t, W}=-M V_{i t} * \sum_{t+1}^{t+1+W} \ln \left(p_{i t} / p_{i t-1}\right)
$$

where $M V_{i t}$ is the market-value of equity (all converted in Euros), $t=06 / 30 / 2011$ and 
$W=130$ (six months). ${ }^{8}$

For predicting realized losses (panel A), Vlab market cap loss has the highest rank correlation (0.832) with the six-month realized loss. However, size only (measured by the market cap) appears to be one of the most important factors predicting the realized ranking with a correlation of 0.812 . The size indeed explains most variations among banks stress test results (more than 50\% as shown by a principal component analysis on the EBA 2011 output). In order to make other systemic risk factors apparent, the subsamples of (very) large banks (with Core Tier 1 capital over $19 \$$ bn) and small banks are treated separately. ${ }^{9}$ The 15 large banks include HSBC, Barclays, BNP Paribas, Deutsche Bank, etc. and are comparable to the 19 US BHCs.

When we look at correlations in the small and large subsamples, the EBA projected total losses are a better predictor of the ranking of realized losses of large banks than Vlab. The correlation of the realized loss with the EBA projected total net loss is negative (except for large banks) since many banks with positive projected profits in the stress test actually endured the highest losses during the sovereign debt crisis.

For predicting realized returns (panel B), the estimated core Tier 1 capital return over the EBA stress scenario is a better predictor of the ranking of realized six-month returns, but Vlab long-run marginal expected shortfall (LRMES) predicts better the amplitude of realized returns according to the root mean square error (RMSE).

\section{Testing stressed capital ratios and shortfalls}

Capital ratios are the most important output of stress tests. They determine which bank failed the test under the stress scenario and the following supervisory measures or recapitalization plans. In US Dodd-Frank-Act stress tests, banks have to pass regulatory thresholds on four ratios each quarter of the stress scenario: the Tier 1 Common Capital Ratio (T1CR), the Tier 1 Capital Ratio (T1R), the Total Risk-Based Capital Ratio (Total $\mathrm{CR}$ ) and the Tier 1 Leverage Ratio (T1 LVGR). ${ }^{10}$ The only ratio to be passed in the EBA stress test is the Core Tier 1 Capital Ratio, which is considered equivalent to the US definition

\footnotetext{
${ }^{8}$ Data source for stock prices and exchange rates: Datastream. Data source for market caps: Vlab. To compare Vlab and EBA forecasting performance, Vlab results are downloaded on the closest date (June 30, 2011) prior the disclosure of the EBA results in July 2011.

${ }^{9}$ The groups of small and large banks were defined according to a hierarchical clustering analysis on the output of the EBA 2011 stress test.

${ }^{10}$ The disclosed ratios are actual ratios before the stress scenario (actual), stressed ratios at the end of the stress scenario (projected) assuming all capital actions, and minimum ratios over the 9 quarters of the stress scenario (min) assuming all capital actions or assuming no capital actions.
} 
of the T1CR. The ratios of four stress tests are reported in Tables 1 (CCAR 2012 and 2013) and 2 (CEBS 2010 and EBA 2011), before and after the application of the stress scenario.

The numerators of ratios are different qualities of capital based on Basel requirements: the Tier 1 common or core capital, the Tier 1 capital, and the Total Risk-Based Capital. Tier 1 common capital (US) and Core Tier 1 capital (EU) are the closest to common shareholders equity. The Total Risk-Based Capital is the addition of Tier 1, Tier 2, and possibly additional Tier 3 capital to cover market risk activities. As for the denominator, the T1 LVGR is the only ratio defined in terms of total assets (average of total assets over the last quarters), the denominators of all other ratios are the risk-weighted assets (RWA).

In order to comply with the regulatory ratio thresholds, banks can either increase their numerator (raise capital) or decrease their denominator (sell assets). As the regulator do not care how banks increase their ratios, banks meeting difficulties to raise fresh capital in bad times are incited to shrink their asset base instead. Multiple firms shrinking their assets then have the potential to create a credit crunch and fires sales, leading to the worsening of the credit crisis (Hanson et al. (2011)). Instead of relying on ratios, the SCAP 2009 lead to a substantial recapitalization of the US financial system by forcing 10 bank holding companies to raise a $75 \$$ bn capital buffer. After the failure of the EBA 2011 stress test to recapitalize the EU financial system, the EBA released in early December 2011 the results of a recapitalization plan of the European financial sector called the "Capital Exercise". The EBA Capital Exercise is not a stress test (no stress scenario) but recommended the creation of a 115 EUR bn capital buffer (including 30 EUR bn for Greek banks) ${ }^{11}$ to restore market confidence during the European sovereign debt crisis. The capital buffer estimates of stress tests are also shown in Tables 1 and 2 .

\subsection{Stress tests vs. Vlab ratio}

Vlab equivalent to the estimated capital shortfalls of stress tests is the market-based estimate SRISK (eq. (1)). To facilitate the comparison with stress tests ratios, we define the Vlab market leverage ratio under stress $\left(\mathrm{M}-\mathrm{LVGR}_{s}\right)$ as the ratio of market cap to quasimarket assets under Vlab stress scenario

$$
\text { Vlab M-LVGR }{ }_{s}=\frac{M V(1-L R M E S)}{M V(1-L R M E S)+D}
$$

\footnotetext{
${ }^{11}$ Greek banks are treated separately in the EBA capital exercise where their capital buffer is defined in order not to conflict with pre-agreed arrangements under the EU/IMF program (European Banking Authority (2011c)).
} 
The total estimated capital shortfalls and the cross-sectional average of ratios of Vlab and stress tests are reported in Table 3. The severity of Vlab SRISK and M-LVGR $s$ is in striking contrast with stress tests estimates for all stress tests. This is consistent with the finding of Hanson et al. (2011) that regulatory ratios are not a binding constraint for banks whereas the market is. The difference is even more obvious in Europe where the capital shortfall estimates of the last two stress tests (resp. 0.2 EUR bn in the CEBS 2010 and 1.2 EUR bn in the EBA 2011) appear extremely low compared to the corresponding SRISK (resp. 796 EUR bn and 886 EUR bn).

The stressed individual ratios of US BHCs and large European banks tell us the same story. They are illustrated with their Vlab ratios in Appendix B for the last European stress test (EBA 2011) and the two last US stress tests (CCAR 2012 and 2013). Vlab ratio is almost always more severe than the stressed regulatory ratios, especially in Europe, where all the large banks pass the stress test but none of them passes Vlab test (see Figure B.2a in the Appendix). ${ }^{12}$

Table 4 (panel B) shows the rank correlations between SRISK and the estimated capital shortfalls of stress tests. In the European stress tests, most banks have a zero capital shortfall as the disclosed shortfall is

$$
\text { Disclosed Capital Shortfall }=\max \left(0,\left[k^{\prime} * R W A_{S}-\text { Capital }_{S}\right]\right) \text {, }
$$

where $k^{\prime}$ is the prudential capital ratio threshold used in the stress test $(5 \%$ in the EBA 2011), $R W A_{S}$ and Capital $_{S}$ are respectively the risk-weighted assets and the capital level of a bank at the end of the stress scenario. We actually observe that most European banks end up with a capital excess at the end of the stress scenario (see Figure 5a) when we remove the zero bound and derive the 'absolute' capital shortfall

$$
\text { Capital Shortfall (RWA) }=k^{\prime} * R W A_{S}-\text { Capital }_{S} .
$$

The rank correlation of SRISK with (5) is highly negative, significant and almost the same in the last two European stress tests (-0.791 (CEBS 2010) and -0.790 (EBA 2011), see Table 4). Therefore, banks with the highest estimated capital shortfall in Vlab are considered to be the safest and the most well capitalized banks in European stress tests. The size however also plays a role in this result as the correlation with SRISK decreases for small banks (-0.53,

\footnotetext{
${ }^{12}$ The threshold for both American and European regulatory ratios (in blue) is $5 \%$. Vlab uses a threshold $k$ of $8 \%$ in the US case and $5.5 \%$ in the EU due to the divergences in accounting standards.
} 
in the EBA 2011 stress test) and is not significant in the group of large banks.

All the most systemically important institutions according to SRISK end up with large capital excess at the end of the stress scenario of European stress tests. We show this result in Figure 5a for the 2011 EBA stress test and obtain a similar pattern for the stress test of 2010. Changes in the capital shortfall/excess estimates from 2010 to 2011 are also not always consistent between Vlab and stress tests. The biggest changes in stress tests estimates are observed for Barclays and the Royal Bank of Scotland, that appear to have reduced capital excess in 2011, but the Royal Bank of Scotland sees its SRISK declining too as the bank was less leveraged in 2011. Banco Santander and Intesa Sanpaolo experienced the largest SRISK increases between 2010 and 2011 as both banks grew in size (larger market cap), in risk (larger LRMES) and in leverage for Banco Santander. Contrastingly, the capital excess of Banco Santander remains the same in the 2011 stress test and increases for Intesa Sanpaolo.

It is hard to believe that the European financial sector was so well capitalized when the EBA stress test was disclosed in July 2011. The estimated SRISK of Dexia of 26 EUR bn at the end of June 2011 appears more credible than the EBA capital excess of 7.9 EUR bn, knowing that Dexia was the first bank to be bailed out in the context of the European sovereign crisis in October 2011. The resolution plan of Dexia included the sale of its Belgian banking subsidiary for 4 EUR bn to the Belgian government, the sale of some of its assets and businesses, and guarantees of up to 90 EUR bn provided by Belgium, France and Luxembourg. ${ }^{13}$ The resolution plan lead to a net loss of 11.6 EUR bn for 2011 due to the discounted sales of assets.

Another piece of evidence of the failure of the 2011 stress test comes from the EBA own estimates, five months later, of an "exceptional and temporary capital buffer to address current market concerns over sovereign risk and other residual credit risk related to the current difficult market environment". The recommended capital buffer (the "Overall Shortfall") of 115 EUR bn, well above the 2.5 EUR bn of the EBA stress test, is defined by

$$
\text { EBA Overall Shortfall }=\max (0,[0.09 * R W A-T 1 C])+B u f f S O V,
$$

where $B u f f S O V \geq 0$ is an additional capital buffer for sovereign debt exposures in the European Economic Area (EEA). The overall shortfall is not the outcome of a stress test but is the result of three main drivers: the target 9\% T1 core capital ratio (instead of 5\%), the application of Basel 2.5 to derive risk-weighted assets (increasing the capital requirement

\footnotetext{
${ }^{13}$ Dexia agrees to Belgian bail-out, Financial Times, October 10, 2011.
} 
for market risk), and the sovereign buffer on EEA sovereign debt exposures (one third of the buffer). ${ }^{14}$ The rank correlation of SRISK with the EBA overall shortfall is positive (0.163) but not significant at 5\%. The exercise corrected for the underestimated sovereign risk weights with the additional sovereign capital buffer but many SRISK-top banks like Crédit Agricole still had zero capital shortfall in the EBA Capital Exercise (see Figure 4b). We may argue that the estimates of the exercise were still too low compared to SRISK (see Table 3) and arrived too late in December 2011 as many banks were already in deep financial trouble. Dexia, with 6.3 EUR bn shortfall in the exercise and 21.7 EUR bn SRISK, was bailed out a second time for 5.5 EUR bn by French and Belgian governments in November 2012 and reported a net loss of 2.9 EUR bn for 2012. ${ }^{15}$ Crédit Agricole, with no capital shortfall in the exercise but a 88 EUR bn SRISK, announced a net loss of 6.5 EUR bn for $2012 .{ }^{16}$

The rank correlations in the last part of Table 4 (panel C) reveal two important components driving stress tests and Vlab rankings apart: the capital actions and the risk-weighted assets. The aggregate outcome of stress tests with and without the effect of capital actions is presented in Tables 1 (US) and 2 (EU). The impact of capital actions on ratios is negative in the CCAR since capital actions are capital distribution plans (submitted as part of the CCAR). Conversely, capital actions are capital raising plans in the SCAP and the EBA and have a positive impact on stress tests outcomes. ${ }^{17}$ For all stress tests, rank correlations with Vlab measures increase when capital actions are ignored. We show in the next section, that rank correlations also increase substantially when risk-weighted assets in stress tests measures are replaced by total assets.

\subsection{Risk-based capital vs. leverage}

The assessment of banks leverage using a Tier 1 leverage ratio (T1 LVGR) defined as the ratio of Tier 1 capital to total assets is a recommendation of Basel III to supplement the risk-based regime (Basel Committee on Banking Supervision (2011)). Haldane (2012) shows

\footnotetext{
${ }^{14}$ European Banking Authority (2011c)

${ }^{15}$ Fresh Franco-Belgian bailout for Dexia, Financial Times, November 8, 2012. Dexia at 'turning point' amid more losses, Financial Times, February 21, 2013.

${ }^{16}$ Second year in red for Crédit Agricole, Financial Times, February 20, 2013.

${ }^{17}$ Capital actions in the CCAR 2012 include all proposed future capital distribution plans (issuance of capital instruments, dividends payments and share repurchases) throughout the stress scenario. In the EBA 2011, capital actions include issuance of common equity, government injections of capital and conversion of lower-quality capital instrument into Core Tier 1 capital. The EBA additionally considers the effect of mandatory restructuring plans and the final outcomes only consider mandatory measures announced before disclosure. In the SCAP, the capital actions include the proposed capital actions and the effects of the results of the first quarter of 2009. The correlation between SRISK and the SCAP capital buffer also increases from 0.507 to 0.562 when capital actions are not included.
} 
that this ratio significantly predicts the failure of financial firms whereas the risk-based core Tier 1 capital ratio (T1CR) does not.

In the CCAR 2012, two banks (Citigroup and MetLife) failed the T1 LVGR under the stress scenario. In the CCAR 2013, Goldman Sachs has the lowest stressed leverage ratio followed by Morgan Stanley and JP Morgan, and two firms (Ally Financial and American Express) fail the T1 LVGR under stress when considering the effect of their original submissions of planned capital actions. We build a Tier 1 leverage ratio for the European banks of the EBA stress test and find that Deutsche Bank would have failed the stress test if the Basel III 3\% T1 LVGR backstop existed. In Figure 3, the visual correlation between the market leverage ratio under Vlab stress $\left(\mathrm{M}-\mathrm{LVGR}_{s}\right)$ and the stressed Tier 1 leverage ratios appears to be strong in the last US and European stress tests (CCAR 2013 and EBA 2011). This result is confirmed in Table 4 (panel C); the rank correlation with Vlab M-LVGR increases from 0.581 to 0.877 when the RWA, the denominator of capital ratios, are replaced by total assets in the CCAR 2013. We obtain similar results one year earlier with the CCAR 2012, and in Europe with the 2011 EBA stress test.

The contrast between risk-based and leverage-based stress tests outcomes is even more obvious when the stress test capital shortfall is written as a function of total assets. We show in Table 4 (panel B) and Figure 5b that the correlation between SRISK and the capital shortfall of the EBA stress test becomes highly positive (0.679) and significant when the EBA shortfall is written as a function of total assets instead of risk-weighted assets. The leverage-based capital shortfall is given by

$$
\text { Capital Shortfall }(\mathrm{TA})=k * T A_{S}-\operatorname{Capital}_{S} \text {, }
$$

where $k$ is the same prudential ratio used in Vlab (5.5\% for European banks), and $T A_{S}$ are the total assets of the bank at the end of the stress scenario. The result holds when we control for the size; the rank correlation between (7) and SRISK remains high and significant at $1 \%$ in the groups of small (0.634) and large banks (0.743). With this definition, the EBA shortfall would have increased from 1.2 EUR bn to 372 EUR bn, which is still less severe than SRISK (886 EUR bn) for a sample of $53 \mathrm{EU}$ banks. Dexia would have been forced to raise 9.5 EUR bn in July 2011, and Crédit Agricole 35.8 EUR bn, with the leverage-based shortfall of eq. (7).

\subsection{EU-US differences}

The ultimate impact of the stress scenario is a decline in capital ratios under both US and EU stress tests. However, this result comes from a diminution of capital (numerator) 
in the US whereas increasing RWA (denominator) is the main driver of lower capital ratios in Europe (see Tables 1 and 2). We will see in the next section that RWA definitions are however not the same; RWA are derived under Basel I in the US (before 2013), under Basel II in the EU.

Stress tests of the Federal Reserve focus on the 19 largest US BHCs whereas European stress tests concern 90 banks representing $65 \%$ of the assets in the EU banking sector. We can expect more heterogeneity in the 90 banks of $21 \mathrm{EU}$ countries due to their different size and business models.

Other differences come from different stress scenario trajectories and assumptions on the balance sheet growth. The SCAP 2009, the CEBS 2010 and the EBA 2011 have a static balance sheet evolution assumption whereas the CCAR assumes that the size of the balance sheet can change according to economic conditions. US stress scenario tend to revert to a 'normal state' of the world at the end of the scenario, unlike the EBA which assumes further deterioration of the economic situation the second year of the stress scenario. This is the reason why the Federal Reserve considers minimum ratios over the scenario horizon to determine who failed the stress test, while European stress tests consider ratios at the end of the stress scenario.

Overall, different definitions, samples, assumptions and scenarios lead to a RWA fall of $6.1 \%$ at the end of the supervisory stress scenario of the CCAR 2012 and a RWA increase of 14\% under the EBA 2011 adverse scenario. Moreover, the leverage ratio cannot reflect the European stress scenario as the stress appears in risk weights and total assets are assumed constant over the scenario. The stressed leverage ratios also decline less in the US than the stressed risk-based ratios. The impact of the projected total assets and RWA changes on US ratios is however not straightforward according to the Federal Reserve.

\section{Testing the efficacy of regulatory risk weights}

A major difference between Vlab and stress tests measures comes from the denominator of regulatory ratios. Regulatory ratios and shortfalls are expressed as a function of riskweighted assets whereas Vlab uses quasi-market assets. We have shown in Section 4.2 that the European financial sector would have ended up better capitalized if stress tests had relied on a simple leverage ratio instead of the complex regulatory capital ratios standardized by risk-weighted assets. We therefore argue that the forbearance of stress tests outcomes (especially in Europe) comes rather from the regulatory risk weights, than from the stress tests methodologies. 


\subsection{Basel I and Basel II}

Risk-weighted assets (RWA) definitions are not the same in US and European stress tests; RWA are derived under Basel I in the US (before 2013), under Basel II in the EU. This leads to important differences in risk measures and stress tests models. Risk weights are fixed for different asset categories under Basel I whereas banks can use their own models to derive RWA under Basel II.

Under Basel I, RWA are defined such that assets are assigned to four different asset categories with different risk weights $(0 \%, 20 \%, 50 \%, 100 \%)$. These four categories could be roughly described as exposures to sovereigns (0\%), banks (20\%), mortgages (50\%), and corporates (100\%). In the SCAP, the rank correlation of SRISK was indeed the highest with the most risky asset category. But Basel I risk weights cannot reflect the risk evolution of the different asset categories; in 2011, SRISK becomes more correlated with the zero-weight risk category (including sovereign debt exposures) than with the most risky 100\%-weight category.

The definition of risk-weighted assets under Basel II incorporates credit risk, operational risk and market risk components. The capital requirement for credit risk remains the most important component (around $80 \%$ of RWA) and is defined in terms of exposures at default (EAD) and risk parameters. Risk parameters (probability of default and loss given default) are used to assign weights to each exposure. In the EBA 2011 stress test, the increase of RWA under the stress scenario comes from the credit risk component; the changes are located in risk-weights (stressed LGDs and PDs) since EADs are considered invariant under the static balance sheet assumption. This is a major difference with the US methodology that considers fixed risk weights, even if credit rating migrations are allowed. The RWA methodology is however updated in the CCAR 2013 where the stressed RWA also include BHCs' projections of a market risk component defined under the stricter Basel 2.5 market risk rule.

Concerns on the robustness of Basel II risk weights have been raised in Haldane (2012), given the degree of over-parametrization of RWA and the risk parameter estimates purely based on in-sample statistical fit over short historical samples. The use of banks internal models to derive their risk parameters under the Internal-Rating-Based (IRB) approach of Basel II has also been criticized. First, Basel II was designed such that the use of banks internal models would allow them to derive lower RWA in order to incite banks to update their risk management practices. Le Lesle and Avramova (2012) indicate that this resulted in lower RWA under Basel II, and therefore lower capital charges than under Basel I whereas 
the internal models did not necessarily conduct to lower risks. Second, concerns about the consistency of risk weights across firms have been raised in Haldane (2011, 2012); Le Lesle and Avramova (2012). The Basel Committee on Banking Supervision (2013) confirmed these concerns showing in their "Regulatory Consistency Assessment Programme" (RCAP) that differences in risk weights (in the trading book) across firms reflect modeling choices and supervisory decisions rather than actual risk taking. Third, the internal models used to derive risk weights are completely opaque. Haldane (2012) indicates that risk weights are black boxes that investors do not understand or trust. These concerns have important implications for the European stress tests outcomes knowing that 59 of the 90 participating banks in the EBA 2011 stress test are IRB banks, i.e. use their own models to derive risk weights under the stress scenario.

\subsection{Stress tests vs. Vlab risk weight}

Acharya et al. (2012) establish a connection between Vlab estimates and regulatory riskweighted assets by defining the effective aggregate market risk weight to total assets corresponding to a SRISK of zero. Vlab aggregate risk weight is

$$
\text { Vlab risk weight }=(1-(1-k) * L R M E S)^{-1}
$$

and is comparable to the aggregate regulatory risk weight defined by the ratio of RWA to total assets (also called RWA density in Le Lesle and Avramova (2012)). The risk weight could be interpreted as an aggregate measure of risk per unit of asset; the smaller the risk weight, the less risky the asset holdings of a bank.

As Vlab risk weight is conditional on a crisis, we compare it to the stressed aggregate risk weights of stress tests. Figure 6a compares the projected risk weight at the end of the EBA stress scenario with the Vlab risk weight. These measures of risk have nothing in common; the rank correlation is negative (-0.238) and not significant at 5\%. Dexia and Crédit Agricole are among the riskiest banks according to the Vlab measure and among the safest with the stress test risk weight: both banks have values above the $75 \%$ quantile of the Vlab risk weight distribution while they both appear below the $25 \%$ quantile of the EBA risk weight distribution.

\subsection{Forecasting risk during the European sovereign debt crisis}

This section empirically validates the risk measures of stress tests and Vlab as aggregate measures of bank risk during a crisis. To that end, we compare the performance of these measures to predict a realized measure of risk; the six-month realized volatility defined by 


$$
R V_{i, t, W}=\sqrt{\frac{1}{W} \sum_{t+1}^{t+1+W}\left(r_{i t}-\bar{r}_{i t, W}\right)^{2}}
$$

where $W=130$ days (six months), $\bar{r}_{i t, W}$ is the six-month forward average return of bank $i$ at date $t$ (the disclosure date of the EBA stress test). A striking result appears in Table 5 (panel C) where only Vlab risk weight predicts the ranking of banks realized risk. The rank correlation between the realized volatility and the stress test risk weight is negative and not significant. This result is consistent with the results of Haldane (2012); Le Lesle and Avramova (2012) and the RCAP of the Basel Committee showing that risk weights are not consistently derived across firms. Instead, banks game the RWA by reallocating their assets according to risk weights but this strategy does not necessarily lead to lower risks. Das and Sy (2012) also studied the predictive power of risk-weighted assets and find that RWA do not, in general, predict market measures of risk.

The absence of correlation between the stressed risk weights and the realized risk of banks during a crisis shows furthermore that Basel risk weights are also used for regulatory arbitrage in a macro stress test. Risk weights have no predictive power as they are derived from accounting data and therefore, can only be updated ex-post. The absence of predictive power of stressed risk weights during the European sovereign debt crisis also supports the argument of Haldane (2012) that risk-weighting is suboptimal in an uncertain environment.

We reproduce the results of Das and Sy (2012) for the banks in the EBA stress test with the difference that we use stressed risk weights instead of the actual ones. Different risk factors are regressed on the realized volatility measure in (9) and the estimated coefficients are presented in Table 6. Each column is a different regression with a different set of independent variables. To show the individual effect of each independent variable, the first five columns report the coefficients of univariate regressions. According to the goodness-of-fit measures of the univariate regressions, the book-to-market ratio is the most important factor followed by Vlab risk weight, and the stressed Tier 1 leverage ratio. The table also shows that the parameter of the EBA stressed risk weight (column 5) is not significant to predict realized volatility.

The EBA stressed risk weight parameter becomes however positive and significant when we control for other risk factors. In column 7, a multivariate regression includes all risk factors and the parameters are all significant at the $1 \%$ level (except the constant). Moreover, the adjusted $R^{2}$ increases from $53.18 \%$ to $61.29 \%$ (from columns 6 to 7 ) when the EBA stressed risk weight is added to the regression. These results suggest that regulatory risk weights can 
bring additional information on risk once we account for other more important risk factors like the book-to-market ratio, Vlab risk weight and the leverage ratio.

A final validation test looks at the change in risk from the disclosure of the EBA 2011 to six months after disclosure. Specifically, we assess how the change in EBA risk weights over the stress scenario predict the realized change in risk defined by $R V_{i, t, W}-R V_{i, t-W, W}$. We show in Table 5 (panel D) that the change in Basel II risk weights, i.e. the stress on PDs and LGDs, is well correlated to the realized risk change of small banks. We conclude that even if the EBA stressed risk weight is individually a wrong measure of the aggregate bank risk, the stress model applied on risk weights is right. Projected changes in risk weights indeed predict the ranking of banks' risk increases during the European sovereign debt crisis.

Vlab risk weight also predicts well the change in risk suggesting that the risk measure does not only predict a risk level but also reflects investors expectations on banks' risk evolution.

\subsection{Portfolio choice under regulatory risk weights}

We demonstrate in this section the weakness of Basel regulatory risk weights as an aggregate measure of bank risk where the bank is seen as a portfolio of assets. The bank chooses its allocation of resources to maximize its return subject to a tolerable level of risk. Regulators implement several standards of prudent risk but these may sometimes be misguided. Here we consider the allocation of a fixed investment budget to asset categories subject to the regulatory requirement implemented in a stylized version of Basel standards.

Let $T A$ be the total assets to be allocated between cash, $C$ (equivalent to the capital requirement for credit risk in Basel II), and other risky assets. Let there be $N$ risky assets with conditional expected returns given by the $(N \times 1)$ vector $m$, and conditional covariance matrix given by the $(N \times N)$ matrix $H$. According to Basel rules, each of these assets has a risk weight $w_{j}$ between zero and one which we assemble in a $(N \times 1)$ vector $w$. The solution is a $(N \times 1)$ vector of dollars to be invested in each asset, $q$. The vector $q$ will also determine the optimal exposures at default under Basel II and the optimal RWA, $w^{\prime} q$. The risk budget requires that $C \geq k w^{\prime} q$, where $k$ is the prudential capital ratio and $C=T A-\iota^{\prime} q$, where $\iota$ is a $(N \times 1)$ vector of ones.

To maximize asset returns subject to these constraints the firm must solve

$$
\begin{gathered}
\max _{q} q^{\prime} m \\
\text { s.t. } T A-\iota^{\prime} q \geq k w^{\prime} q, \quad q \geq 0
\end{gathered}
$$


The Lagrangian of this maximization problem is

$$
L(q, \lambda, \mu)=m^{\prime} q-\lambda\left(T A-\iota^{\prime} q-k w^{\prime} q\right)-\mu^{\prime} q
$$

where the scalar $\lambda$ and the $(N \times 1)$ vector $\mu$ are Lagrange multipliers. The first order condition of equation (11) with respect to $q$ is given by

$$
m^{\prime}+\lambda\left(\iota^{\prime}+k w^{\prime}\right)-\mu^{\prime}=0
$$

Multiplying equation (12) by $q$ and recognizing that either $q$ or $\mu$ will be zero for each asset (from the first order condition of (11) w.r.t. to $\mu$ ), then

$$
\begin{aligned}
m^{\prime} q+\lambda\left(\iota^{\prime} q+k w^{\prime} q\right) & =0 \\
m^{\prime} q & =-\lambda T A \\
\lambda & =\frac{-m^{\prime} q}{T A}
\end{aligned}
$$

Replacing $\lambda$ in (12), we obtain

$$
m^{\prime}-\left(\frac{m^{\prime} q}{T A}\right)\left(\iota^{\prime}+k w^{\prime}\right)-\mu^{\prime}=0
$$

Hence all non-zero allocations $q_{j}$, must satisfy

$$
\begin{aligned}
m_{j}-\left(\frac{m^{\prime} q}{T A}\right)\left(1+k w_{j}\right) & =0 \\
\frac{m_{j}}{1+k w_{j}} & =\frac{m^{\prime} q}{T A}
\end{aligned}
$$

Supposing that each asset has a different value of $m_{j}\left(1+k w_{j}\right)^{-1}$, then the maximum will occur if the entire portfolio of the bank $\iota^{\prime} q$ is invested in the asset with the greatest value of this ratio. The amount invested in this asset will be

$$
q_{j}=\frac{T A}{1+k w_{j}}
$$

If there are multiple assets with the same value of this ratio, the performance will be the same for any feasible allocation to these assets.

The main observation is that the risk of a portfolio is always less than or equal to the sum of the risks of its components. The use of risk-weighted assets ignores this portfolio feature of risk and consequently there is no incentive from the regulatory perspective to diversify. 
The only case where this measure is appropriate is when all assets are perfectly correlated.

Then, if the risk weights are underestimated (as banks use their own risk models under Basel II) or are not adjusted to reflect increased risk during a crisis (as observed with Basel I risk weights in the CCAR 2012, and in Das and Sy (2012)), a bank will choose its optimal asset with the most underestimated risk weight and this will automatically lead to excessive leverage. If $w_{j}$ is the risk weight of the optimal asset and since $q_{j}=\iota^{\prime} q=T A-C$, the leverage ratio $C / T A$ from (16) is $1-\left(1+k w_{j}\right)^{-1}$. Consequently, banks will take excessive leverage if their risk weights are not adequately adjusted to more severe economic conditions.

We show that the mechanical relationship between risk weights and leverage also holds empirically after the application of the stress scenario in the European stress test of 2011 (Figure 6b). The rank correlation between stressed risk weights and stressed Tier 1 leverage is 0.62 for 53 European banks and increases to 0.89 for the 15 largest banks.

The theoretical result of (16) also explains the portfolio decisions of many Eurozone banks during the European sovereign debt crisis. Acharya and Steffen (2012) document that the increase of exposures to risky sovereign debt is partly explained by regulatory arbitrage; banks with higher risk weights increased their exposures to risky sovereign debt to reduce the cost of raising fresh capital, as these exposures have a zero capital requirement (zero-risk weight). To a large extent, it also explains the misguidance of stress tests about European banks risks. For example, Dexia was holding a portfolio of risky sovereign bonds of almost a third of its balance sheet largely financed with short-term debt. Acharya and Steffen (2012) further show that this type of behaviour was largly pervasive among Eurozone banks. Therefore, the reliance on Basel risk weights appears not only to have left financial sectors undercapitalized but also incentivized the build up of risky sovereign debt exposures.

\section{Concluding remarks}

This paper provides an assessment of the outcomes of macroprudential stress tests conducted by US and European regulators. Concerns have been raised on the lack of robustness, severity and transparency of stress tests measures. In this paper, we test the risk assessments and outcomes of stress tests against a market-based macroprudential benchmark (Vlab) that addresses many of those concerns.

We find that the projected losses of stress tests and Vlab correlate well and both predict well the actual realized performance of banks under severe economic conditions. Contrastingly, the required capitalization of financial firms in stress tests is found to be rather low and inadequate ex post, compared to Vlab capital shortfall estimate SRISK. We document 
that this discrepancy arises due to the reliance of stress tests outcomes on regulatory risk weights, and especially in European stress tests running under Basel II where the impact of the stress scenario is translated into higher risk weights. For example, Dexia appeared as one of the safest bank in the latest European stress test disclosed in July 2011, but ranked among the riskiest banks in Vlab. Three months later, Dexia was the first bank to be bailed out in the context of the European sovereign debt crisis.

We show that regulatory risk weights of stress tests have no link with the realized risk of banks during a crisis. Risk weights are only informative when we control for other risk factors like a market measure of risk, the leverage ratio and the book-to-market ratio. Furthermore, Basel risk standards based on risk-weighted assets are demonstrated to provide no diversification incentives as they ignore the subadditivity feature of portfolio risk. Therefore, banks are encouraged to invest their entire portfolio on one asset category or exposure according to a false risk measure, and the underestimation of risk weights (as banks use their own models in Basel II) automatically leads to excess leverage. This misguidance on the asset risk-return allocation is likely to hold in future stress tests, despite the new Basel III Tier 1 Leverage ratio, as the reliance on static regulatory risk weights remains under Basel III.

\section{References}

Acharya, V., Brownlees, C., Engle, R., Farazmand, F., Richardson, M., 2010a. Measuring systemic risk. In: Acharya, V., Cooley, T., Richardson, M., Walter, I. (Eds.), Regulating Wall Street: The Dodd-Frank Act and the New Architecture of Global Finance. John Wiley and Sons, Ch. 4.

Acharya, V., Engle, R., Richardson, M., 2012. Capital shortfall: a new approach to rankings and regulating systemic risks. American Economic Review Papers and Proceedings 102:3, 59-64.

Acharya, V., Pedersen, L., Philippon, T., Richardson, M., 2009. Regulating systemic risk. In: Acharya, V., Richardson, M. (Eds.), Restoring Financial Stability: How to Repair a Failed System. John Wiley \& Sons, Ch. 13.

Acharya, V., Pedersen, L., Philippon, T., Richardson, M., 2010b. Measuring systemic risk, Working Paper Stern School of Business. 
Acharya, V., Steffen, S., 2012. The "greatest" carry trade ever?: Understanding eurozone bank risks, preprint.

Adrian, T., Brunnermeier, M., 2010. CoVaR, Federal Reserve Bank of New York Staff Reports No. 348.

Alfaro, R. A., Drehmann, M., 2009. Macro stress tests and crises: What can we learn. BIS Quarterly Review December, 29-41.

Basel Committee on Banking Supervision, June 2011. Basel III: A global regulatory framework for more resilient banks and banking systems, Bank for International Settlements.

Basel Committee on Banking Supervision, 2013. Regulatory Consistency Assessment programme (RCAP) - Analysis of risk-weighted assets for market risk, Bank for International Settlements.

Board of Governors of the Federal Reserve, 2009a. The Supervisory Capital Assessment Program: Design and Implementation, April 24, 2009.

Board of Governors of the Federal Reserve, 2009b. The Supervisory Capital Assessment Program: Overview of Results, May 7, 2009.

Board of Governors of the Federal Reserve, 2011. Comprehensive Capital Analysis and Review: Objectives and Overview, March 18, 2011.

Board of Governors of the Federal Reserve, 2012. Comprehensive Capital Analysis and Review 2012: Methodology and Results for Stress Scenario Projections, March 13, 2012.

Board of Governors of the Federal Reserve, 2013a. Comprehensive Capital Analysis and Review 2013: Assessment Framework and Results, March 14, 2013.

Board of Governors of the Federal Reserve, 2013b. Dodd-Franck Act Stress Test 2013: Supervisory Stress Test Methodology and Results, March 7, 2013.

Borio, C., Drehmann, M., 2009. Towards an operational framework for financial stability: "fuzzy" measurement and its consequences, Central Bank of Chile Working Paper No. 544.

Borio, C., Drehmann, M., Tsatsaronis, K., 2012. Stress-testing macro stress testing: does it live up to expectations?, BIS Working Paper No 369. 
Breuer, T., Jandačka, M., Rheinberger, K., Summer, M., 2009. How to find plausible, severe, and useful stress scenarios. International Journal of Central Banking 5, 205-224.

Brownlees, C., Engle, R., 2011. Volatility, correlation and tails for systemic risk measurement, NYU Working Paper.

Das, S., Sy, A., 2012. How risky are banks' risk-weighted assets? Evidence from the financial crisis, IMF Working Paper WP/12/36.

Engle, R., Jondeau, E., Rockinger, M., 2012. Dynamic conditional beta and systemic risk in Europe, preprint.

European Banking Authority, 2010. Aggregate outcome of the 2010 EU wide stress test exercise coordinated by CEBS in cooperation with the ECB, July 23, 2010.

European Banking Authority, 2011a. 2011 EU-wide stress test: Aggregate report, July 15, 2011.

European Banking Authority, 2011b. 2011 EU-wide stress test: Methodological note, March $18,2011$.

European Banking Authority, 2011c. EBA recommendation on the creation and supervisory oversight of temporary capital buffers to restore market confidence, December 8, 2011.

Flood, M., Korenko, G., 2013. Systematic scenario selection, Office of Financial Research Working Paper 0005.

Galati, G., Moessner, R., 2011. Macroprudential policy - a literature review, BIS Working Papers No 337.

Glasserman, P., Kang, C., Kang, W., 2012. Stress scenario selection by empirical likelihood, preprint. Available at SSRN: http://ssrn.com/abstract $=2101465$.

Goldstein, I., Sapra, H., 2012. Should banks' stress test results be disclosed? an analysis of the costs and benefits, working Paper, Booth School of Business, University of Chicago.

Greenlaw, D., Kashyap, A., Schoenholtz, K., Shin, H., 2012. Stressed out: Macroprudential principles for stress testing, Chicago Booth School of Business Working Paper No. 71.

Haldane, A., 2011. Capital discipline, Bank of England speech, January 9, 2011. URL http: //www . bankofengland.co.uk/publications/documents/speeches/2011/speech484.pdf 
Haldane, A., 2012. The dog and the frisbee, Bank of England speech, August 31, 2012.

URL http://www . bankofengland.co.uk/publications/documents/speeches/2012/speech596.pdf

Hanson, S., Kashyap, A., Stein, J., 2011. A macroprudential approach to financial regulation. Journal of Economic Perspectives 25:1, 3-28.

Harris, T., Herz, R., Doron, N., 2012. Accounting's role in the reporting, creation, and avoidance of systemic risk in financial institutions. In: Fouque, J.-P., Langsam, J. (Eds.), The handbook of systemic risk. Cambridge University Press, available at SSRN: http://ssrn.com/abstract=1987749.

Hirtle, B., Schuermann, T., Stiroh, K., 2009. Macroprudential supervision of financial institutions: Lessons from the SCAP, Federal Reserve Bank of New York Staff Report No. 409.

Huang, X., Zhou, H., Haibin, Z., 2012. Systemic risk contributions. Journal of Financial Services Research 42, 55-83.

Huang, X., Zhou, H., Zhu, H., 2009. A framework for assessing the systemic risk of major financial institutions. Journal of Banking \& Finance 33:11, 2036-2049.

Le Lesle, V., Avramova, S., 2012. Revisiting risk-weighted assets: Why do RWAs differ across countries and what can be done about it?, IMF Working Paper WP/12/90.

Petrella, G., Resti, A., 2013. Supervisors as information producers: Do stress tests reduce bank opaqueness? Journal of Banking \& Finance.

Schuermann, T., 2012. Stress testing banks, Wharton Financial Institutions Center Working Paper No. 12-08. 

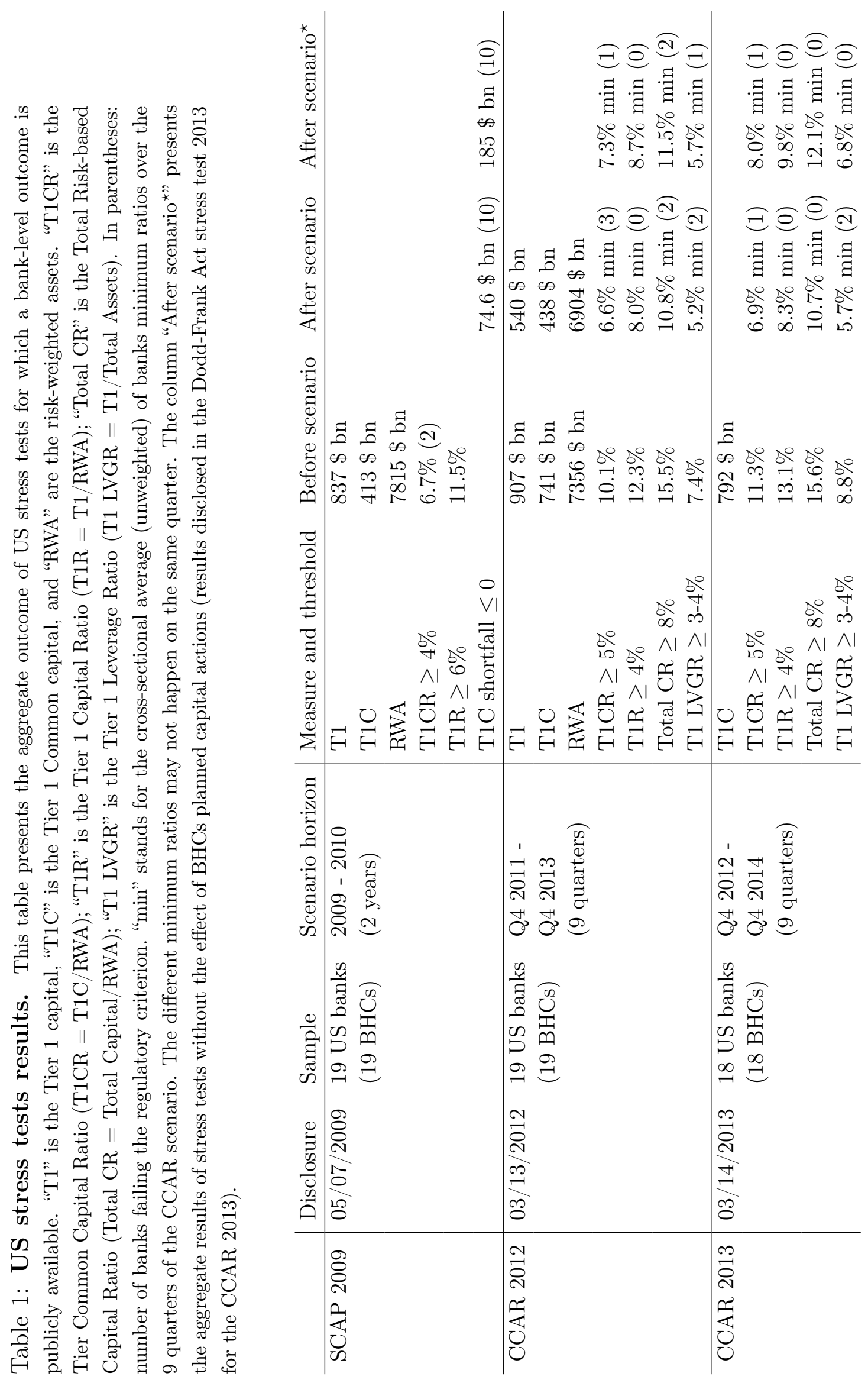


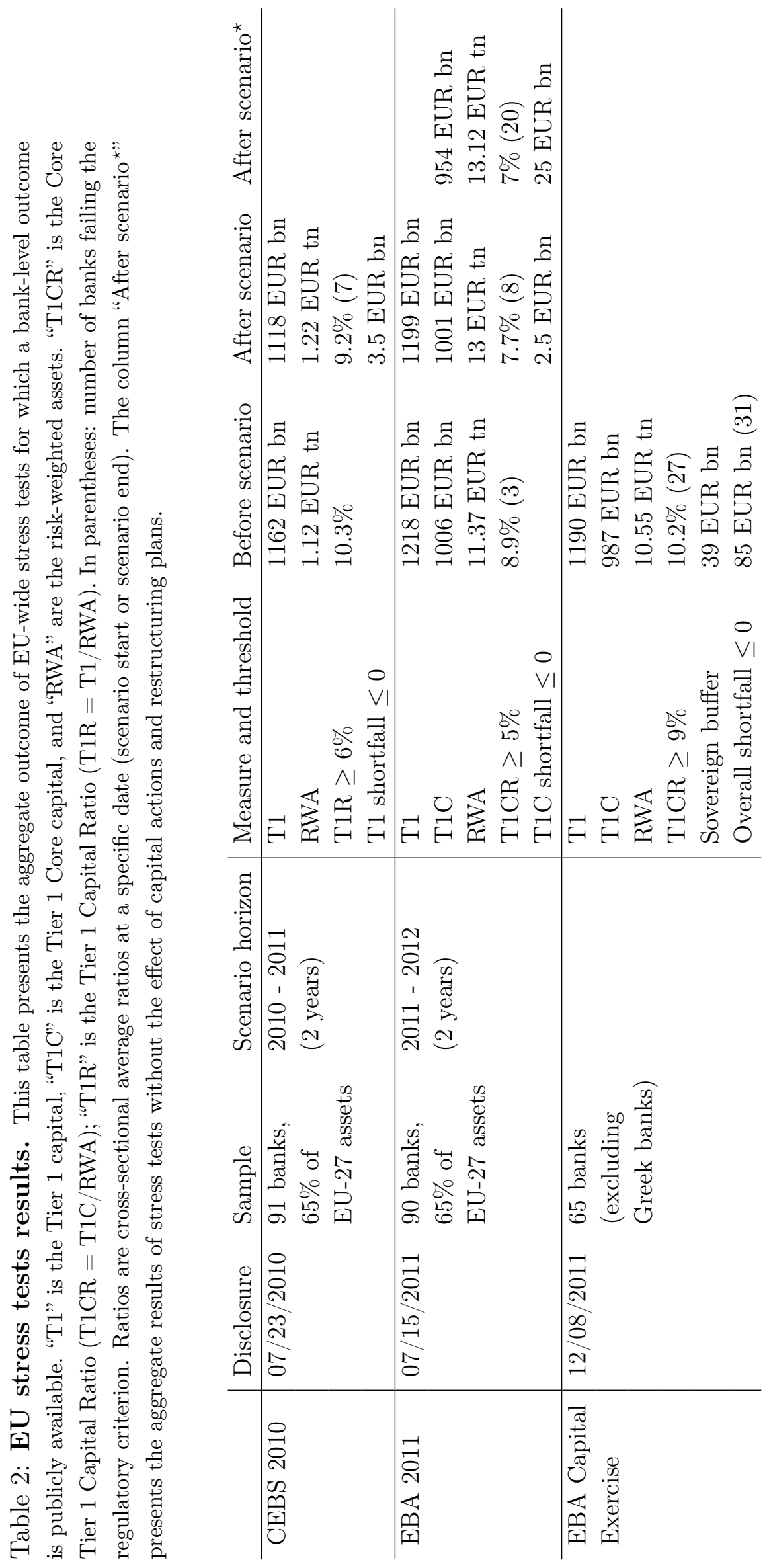




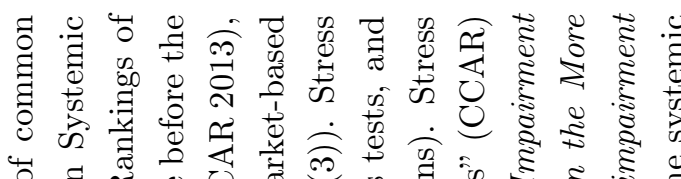
$1,8 y^{2}$ ats

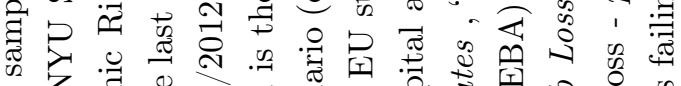

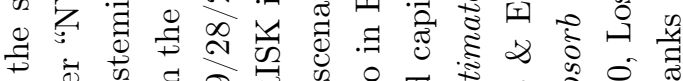

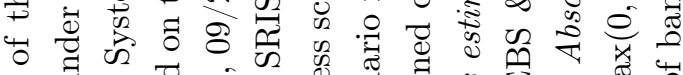

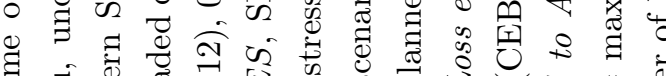
की

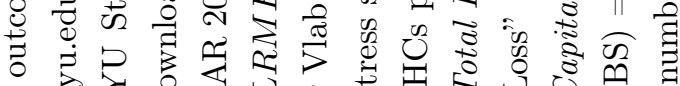

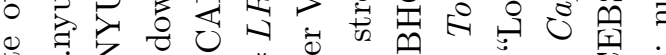

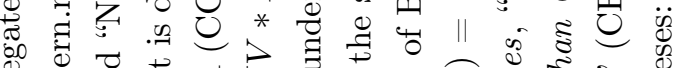

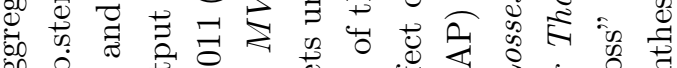

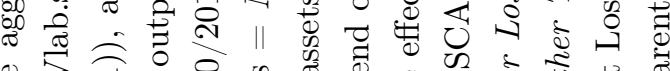

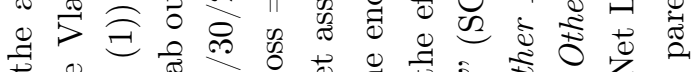

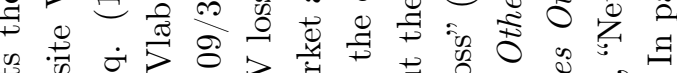

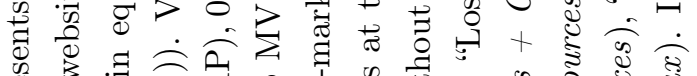

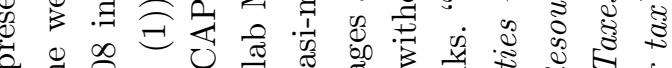

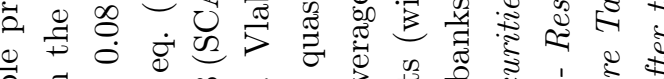

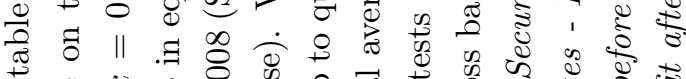

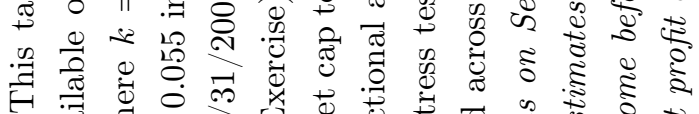

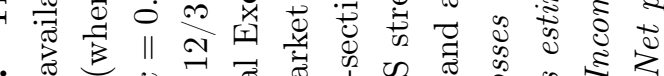

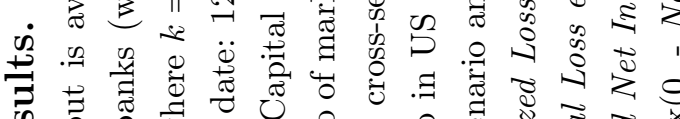
列

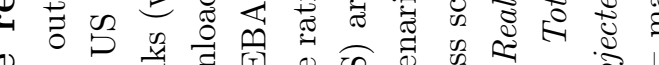

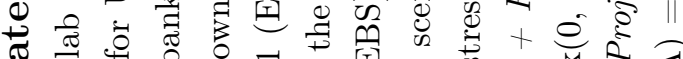

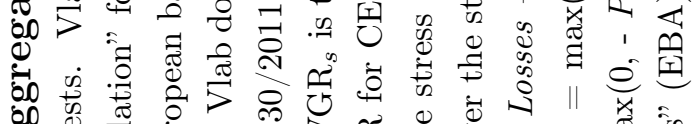

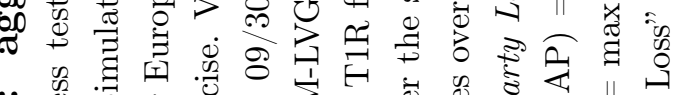

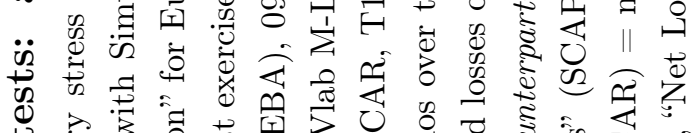

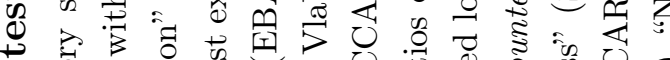

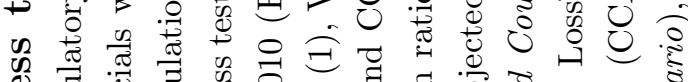

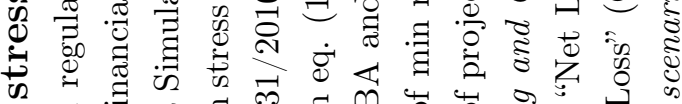

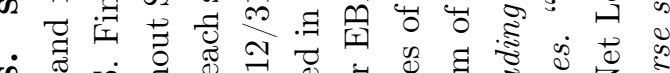

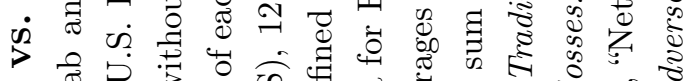
定

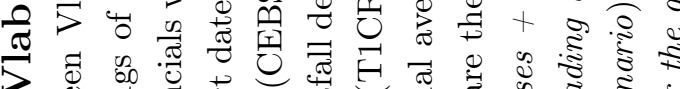

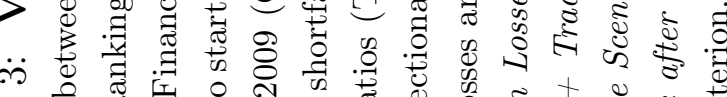

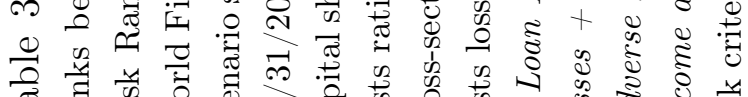

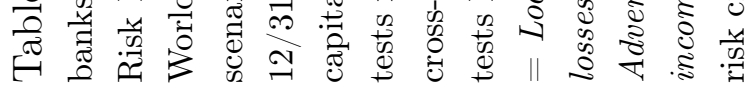

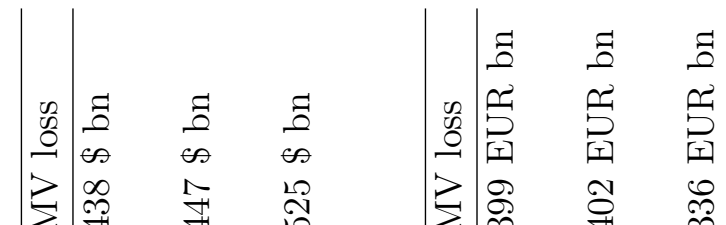

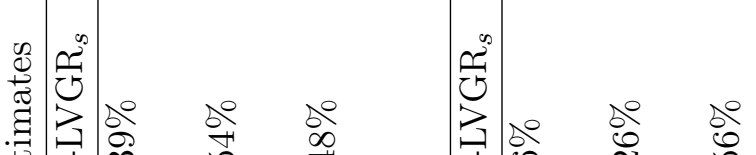

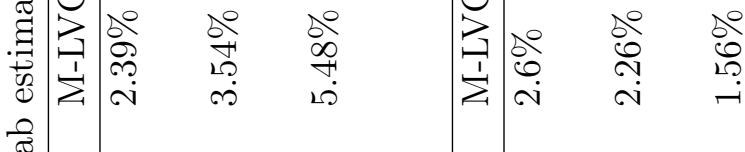

$\stackrel{\frac{\pi}{5}}{>}$

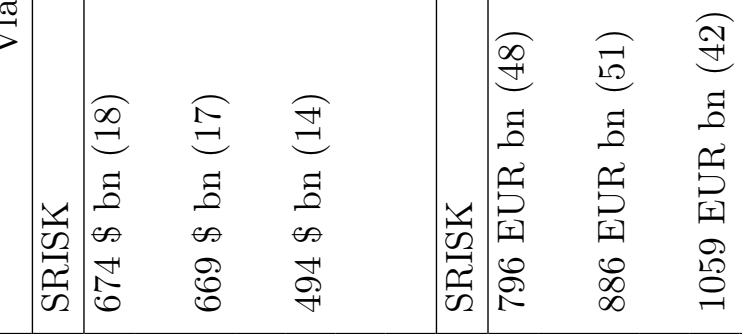

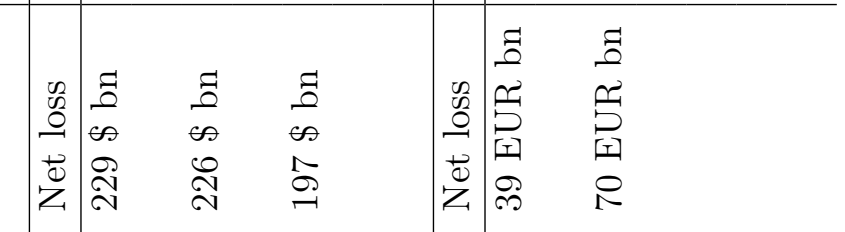

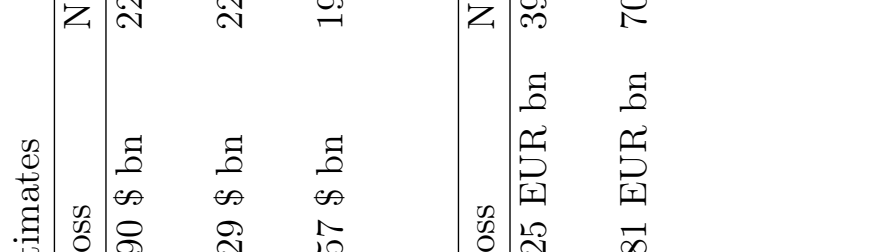

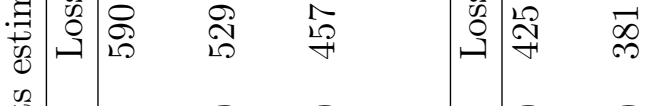

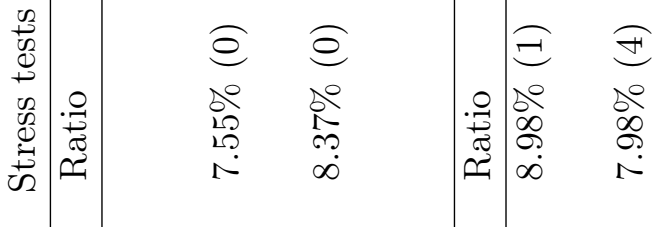

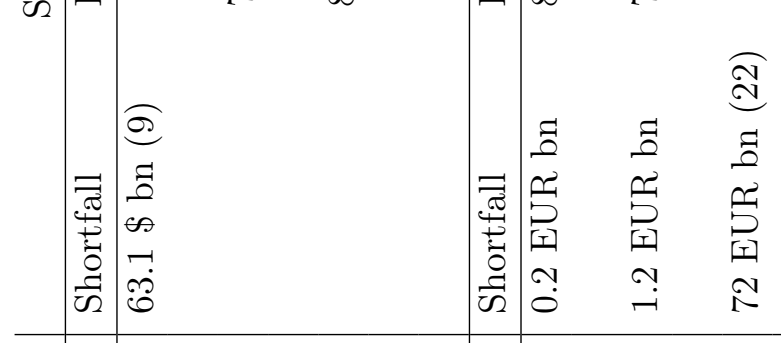

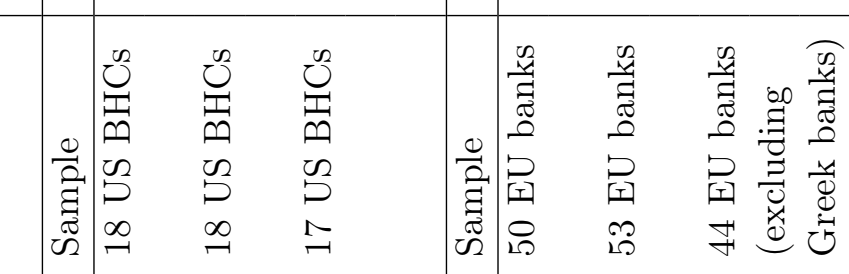

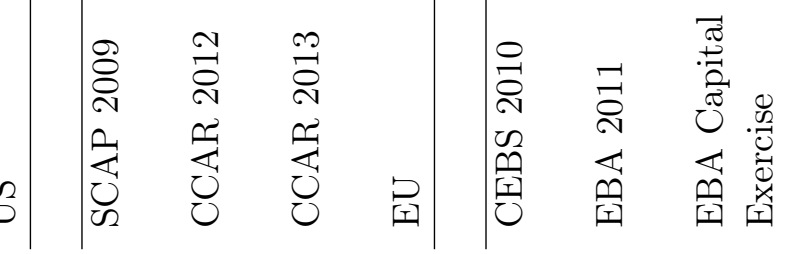




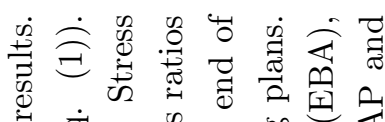

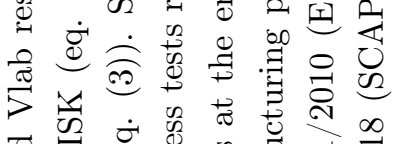

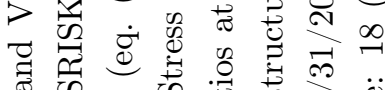

势

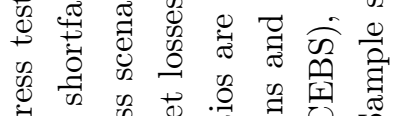

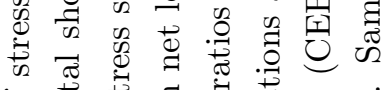

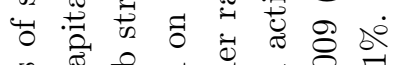

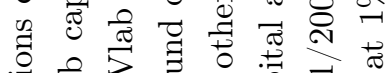

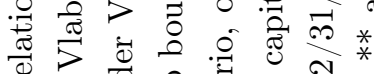

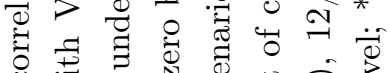

8 者

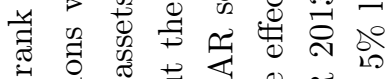

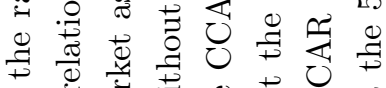

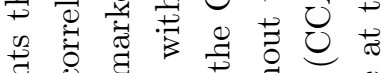

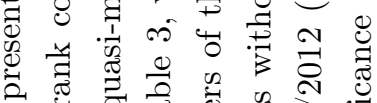

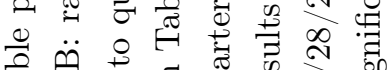

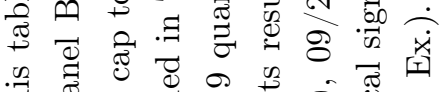

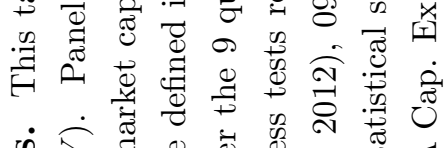

离

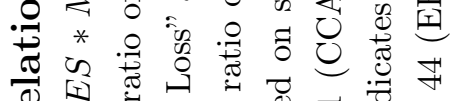

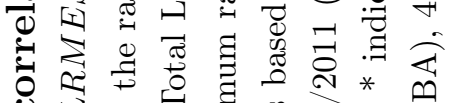

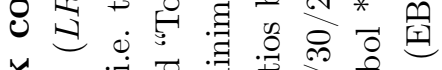

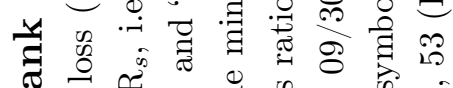

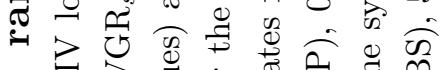

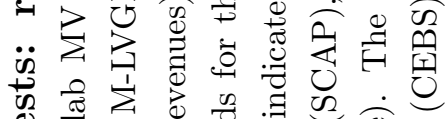

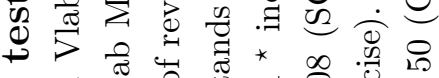

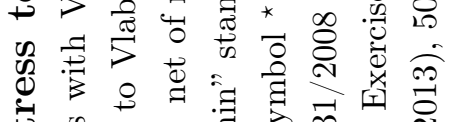

th o

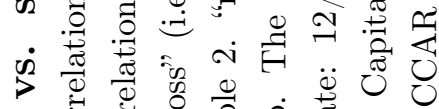

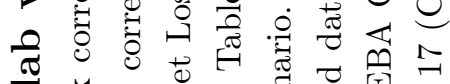

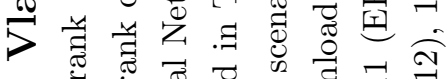

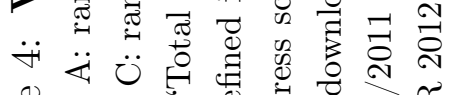

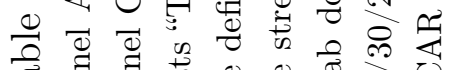

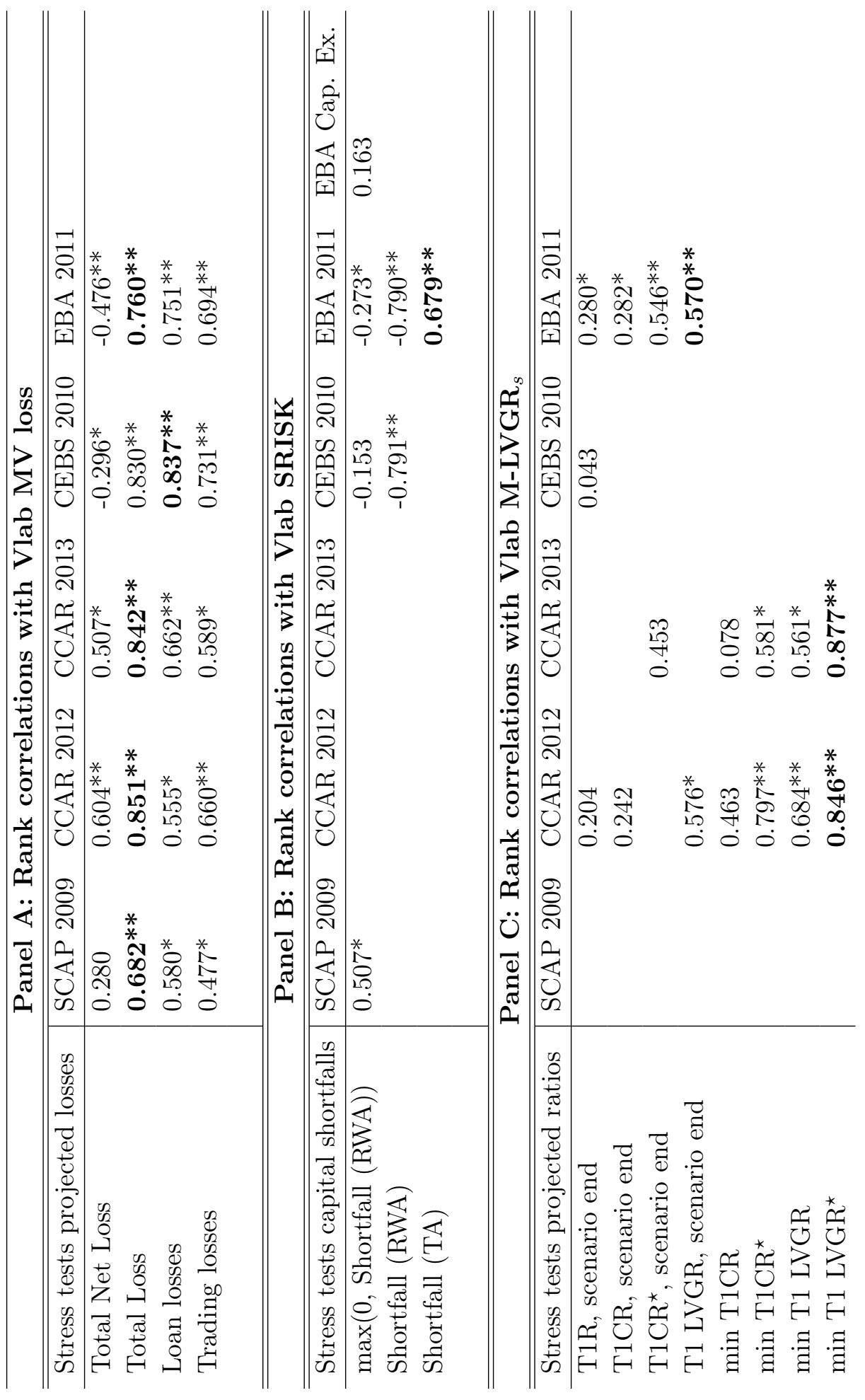

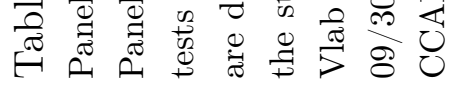


Table 5: Forecasting during the European sovereign debt crisis. This table presents the rank correlations of the EBA and Vlab outcomes with the realized outcomes of banks after disclosure of the EBA stress test in July 2011 (p-values in parentheses). Panel A: rank correlations with the 6-month realized loss (eq. (2)). Panel B: rank correlations with the 6-month realized return $\left(-\sum_{t+1}^{t+131} \ln \left(p_{i t} / p_{i t-1}\right)\right)$. Panel C: rank correlations with the six-month realized volatility $R V_{i, t, 130}$ (eq. (9)). Panel D: rank correlations with

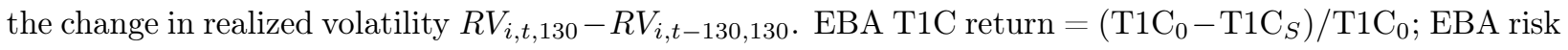
weight $($ scenario end $)=\mathrm{RWA}_{S} / \mathrm{TA}_{S} ; \mathrm{EBA}$ risk weight change $=\mathrm{RWA} / \mathrm{TA}_{S}-\mathrm{RWA}_{0} / \mathrm{TA}_{0}$, where subscript $S$ (resp. 0) denotes quantities after (resp. before) the EBA stress scenario. Vlab output is downloaded before the disclosure date of the EBA stress test: 06/30/2011. Sample size: 15 (large), 38 (small), 53 (all). RMSE: root mean square error on the whole sample.

\begin{tabular}{|c|c|c|c|c|c|}
\hline \multicolumn{6}{|c|}{ Panel A: Rank correlations with the 6-month realized EUR loss } \\
\hline & Estimated losses & Large & Small & All & RMSE \\
\hline Vlab & MV loss & $\begin{array}{l}0.293 \\
(0.289)\end{array}$ & $\begin{array}{l}\mathbf{0 . 6 1 0} \\
(0.000)\end{array}$ & $\begin{array}{l}\mathbf{0 . 8 3 2} \\
(0.000)\end{array}$ & 5086 \\
\hline EBA & Total Net Loss & $\begin{array}{l}0.329 \\
(0.232)\end{array}$ & $\begin{array}{l}-0.100 \\
(0.549)\end{array}$ & $\begin{array}{l}-0.272 \\
(0.048)\end{array}$ & 11202 \\
\hline EBA & Total Loss & $\begin{array}{l}\mathbf{0 . 5 5 7} \\
(0.000)\end{array}$ & $\begin{array}{l}0.527 \\
(0.000)\end{array}$ & $\begin{array}{l}0.803 \\
(0.000)\end{array}$ & 4945 \\
\hline
\end{tabular}

\begin{tabular}{ll|lll|l}
\hline \hline \multicolumn{5}{c|}{ Panel B: Rank correlations with the 6-month realized return } \\
\hline \hline & Estimated returns & Large & Small & All & RMSE \\
\hline Vlab & LRMES & 0.350 & 0.314 & 0.299 & $\mathbf{0 . 5 5 3}$ \\
& & $(0.201)$ & $(0.055)$ & $(0.029)$ & \\
EBA & T1C return & $\mathbf{0 . 5 4 6}$ & $\mathbf{0 . 3 3 9}$ & $\mathbf{0 . 3 5 4}$ & 0.767 \\
& & $(0.035)$ & $(0.038)$ & $(0.009)$ & \\
& & & & \\
\hline \hline
\end{tabular}

\section{Panel C: Rank correlations with the 6-month realized volatility}

\begin{tabular}{|c|c|c|c|c|c|}
\hline & Estimated risk & Large & Small & All & RMSE \\
\hline Vlab & risk weight (eq. (8)) & $\begin{array}{l}\mathbf{0 . 5 5 4} \\
(0.032)\end{array}$ & $\begin{array}{l}\mathbf{0 . 5 6 1} \\
(0.000)\end{array}$ & $\begin{array}{l}\mathbf{0 . 5 3 5} \\
(0.000)\end{array}$ & 3.395 \\
\hline EBA & risk weight, scenario end & $\begin{array}{l}-0.111 \\
(0.694)\end{array}$ & $\begin{array}{l}-0.055 \\
(0.742)\end{array}$ & $\begin{array}{l}-0.140 \\
(0.318)\end{array}$ & 4.539 \\
\hline \multicolumn{6}{|c|}{ Panel D: Rank correlations with the 6 -month realized volatility change } \\
\hline & Estimated risk changes & Large & STmall & All & PMMSE \\
\hline Vlab & risk weight (eq. (8)) & $\begin{array}{l}\mathbf{0 . 5 2 1} \\
(0.046)\end{array}$ & $\begin{array}{l}0.395 \\
(0.014)\end{array}$ & $\begin{array}{l}\mathbf{0 . 4 3 4} \\
(0.001)\end{array}$ & 1.305 \\
\hline EBA & risk weight change & $\begin{array}{l}0.061 \\
(0.830)\end{array}$ & $\begin{array}{l}\mathbf{0 . 3 9 7} \\
(0.014)\end{array}$ & $\begin{array}{l}0.341 \\
(0.012)\end{array}$ & 2.400 \\
\hline
\end{tabular}


Table 6: Realized volatility regressions. Parameter estimates of cross-sectional regressions. Dependent variable: six-month realized volatility (eq. (9)), after disclosure of the EBA stress test in July 2011. EBA T1 LVGR (scenario end) $=\mathrm{T}_{S} / \mathrm{TA}_{S}$; EBA risk weight (scenario end) $=\mathrm{RWA}_{S} / \mathrm{TA}_{S}$, where subscript $S$ denotes quantities at the end of the EBA stress scenario. Vlab download date: 06/30/2011. White's heteroskedasticity-consistent standard errors in parentheses. The symbol * indicates statistical significance at the $5 \%$ level; $* *$ at $1 \%$. Sample size: 53 .

\begin{tabular}{|c|c|c|c|c|c|c|c|c|}
\hline & Regression \# & 1 & 2 & 3 & 4 & 5 & 6 & 7 \\
\hline & Constant & $\begin{array}{l}4.39^{* *} \\
(0.27)\end{array}$ & $\begin{array}{l}-0.44 \\
(1.84)\end{array}$ & $\begin{array}{l}6.25 * * \\
(0.83)\end{array}$ & $\begin{array}{l}5.02^{* *} \\
(0.47)\end{array}$ & $\begin{array}{l}5.95^{* *} \\
(0.94)\end{array}$ & $\begin{array}{l}3.35^{* *} \\
(1.41)\end{array}$ & $\begin{array}{l}1.46 \\
(1.52)\end{array}$ \\
\hline & Book-to-market & $\begin{array}{l}0.03 * * \\
(0.001)\end{array}$ & & & & & $\begin{array}{l}0.031^{* *} \\
(0.001)\end{array}$ & $\begin{array}{l}0.04^{* *} \\
(0.002)\end{array}$ \\
\hline Vlab & risk weight (eq. (8)) & & $\begin{array}{l}2.76^{* *} \\
(0.99)\end{array}$ & & & & $\begin{array}{l}2.901^{* *} \\
(0.68)\end{array}$ & $\begin{array}{l}3.45^{* *} \\
(0.71)\end{array}$ \\
\hline EBA & T1 LVGR, scenario end & & & $\begin{array}{c}-34.47^{*} \\
(16.26)\end{array}$ & & & $\begin{array}{l}-134.98^{* *} \\
(24.24)\end{array}$ & $\begin{array}{l}-177.7^{* *} \\
(16.38)\end{array}$ \\
\hline $\mathrm{EBA}$ & T1 LVGR ${ }^{2}$, scenario end & & & & $\begin{array}{l}-167.78 \\
(126.03)\end{array}$ & & $\begin{array}{l}867.27^{* *} \\
(172.2)\end{array}$ & $\begin{array}{l}997.99 * * \\
(108.3)\end{array}$ \\
\hline EBA & risk weight, scenario end & & & & & $\begin{array}{l}-2.58 \\
(1.59)\end{array}$ & & $\begin{array}{l}4.84^{* *} \\
(1.37)\end{array}$ \\
\hline & F-test & $11.48^{* *}$ & $7.63^{* *}$ & $5.92^{*}$ & 1.76 & 2.5 & $15.77^{* *}$ & $17.47^{* *}$ \\
\hline & Adj. $R^{2}(\%)$ & 16.78 & 11.31 & 8.65 & 1.45 & 2.8 & 53.18 & 61.29 \\
\hline
\end{tabular}


Figure 1: Stress test change in capital vs. Vlab market cap loss (EUR millions). Change in Core Tier 1 Capital (Delta T1C) under the EBA 2011 stress scenario (blue) against Vlab market capitalization loss (Delta MV) (red). Negative changes represent a capital increase. Banks are ranked according to their changes in Core T1 Capital under the EBA stress scenario. Vlab download date: 12/31/2010.

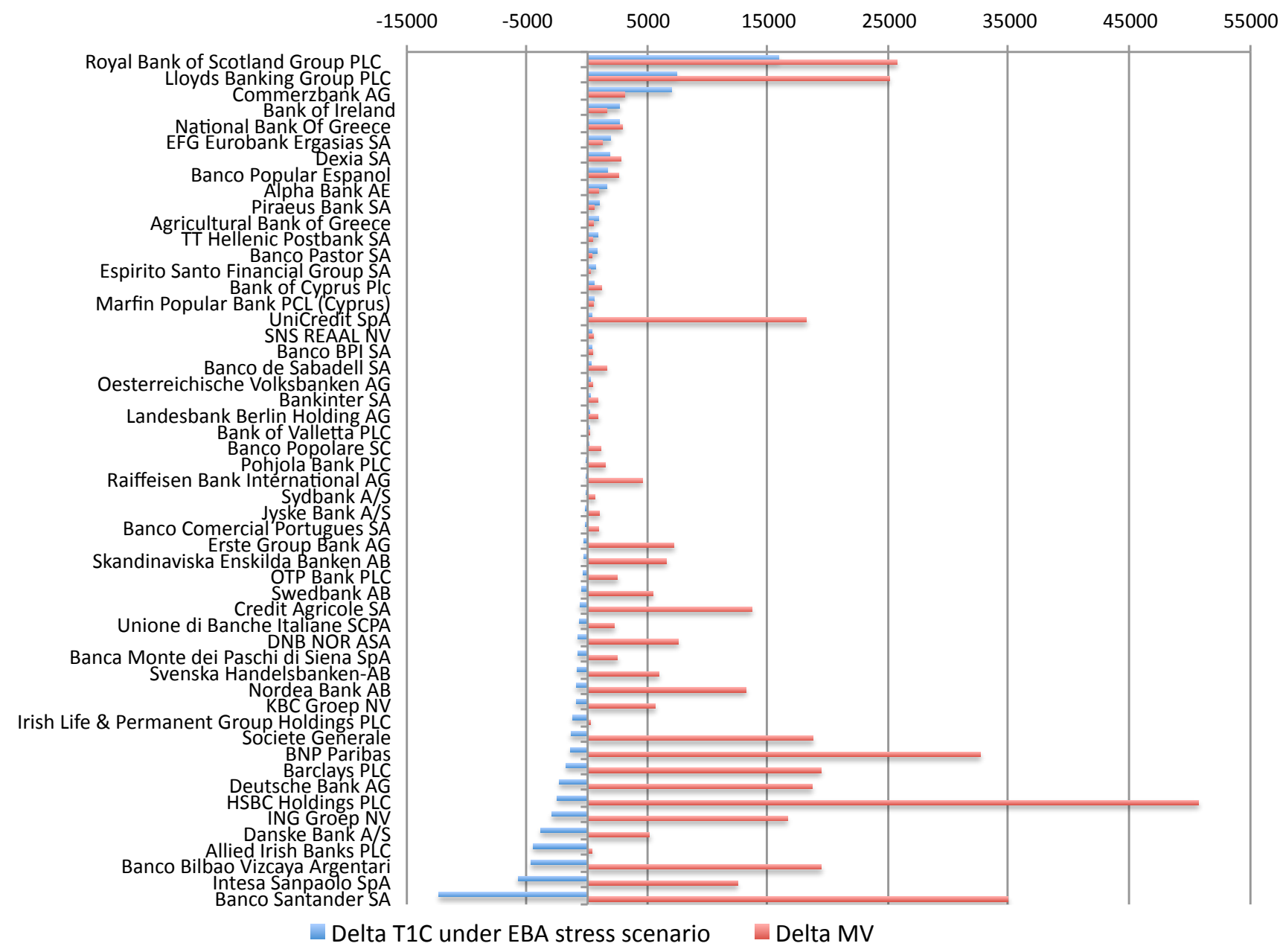


Figure 2: Stress tests context. The lines represent the 6-month forward realized returns of the S\&P500 (red), the Eurostoxx50 (blue) and the MSCI ACWI World ETF index (black). The 6-month forward realized return is derived from daily stock prices $p_{t}$ of the market index: 6-month forward realized return $=\sum_{t=t+1}^{t+131} \ln \left(p_{t} / p_{t-1}\right) * 100$. Vertical bars represent the disclosure date of each stress test (in red for US stress tests, blue for European stress tests).

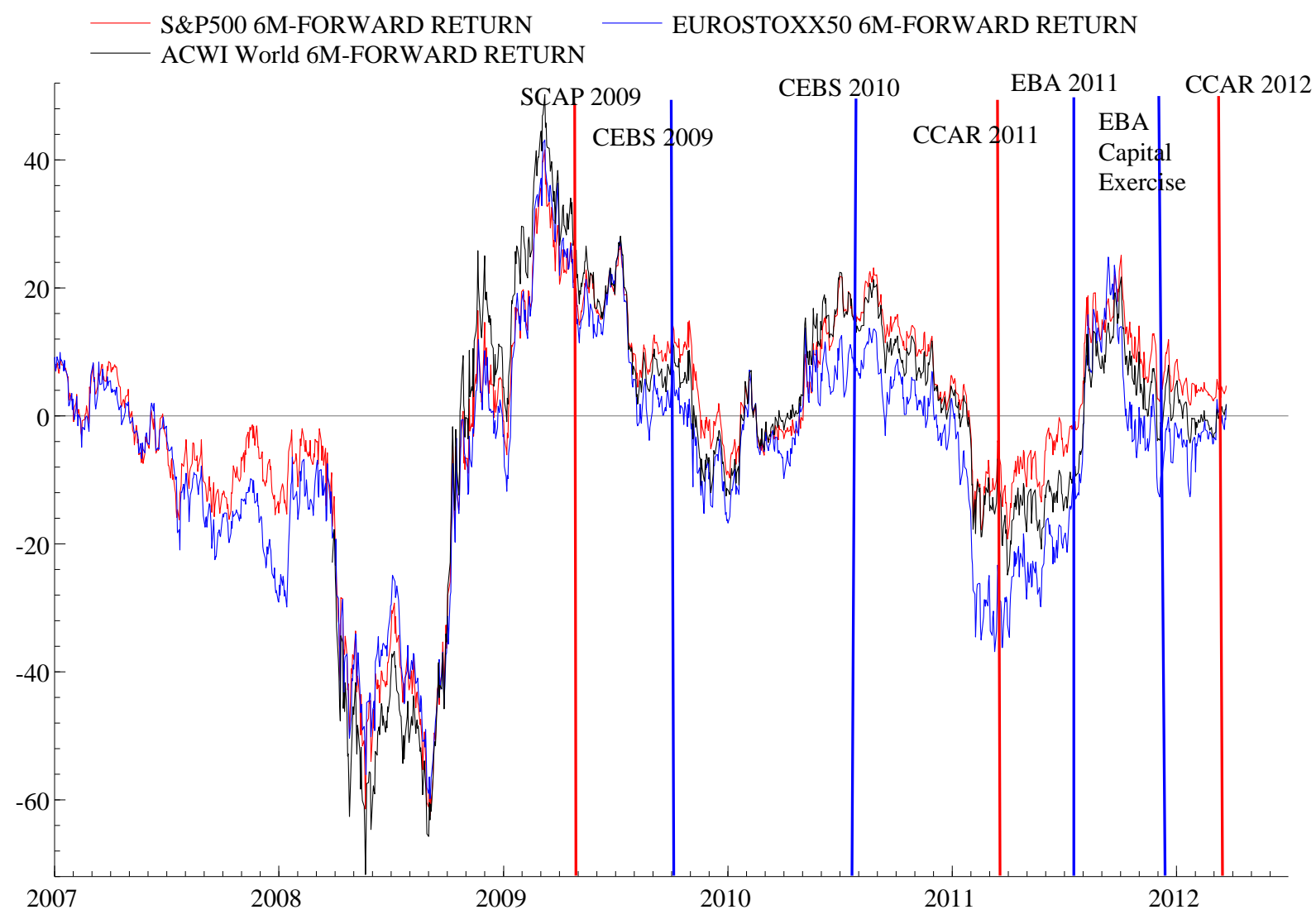


Figure 3: Stress tests Tier 1 leverage ratios vs. Vlab market leverage ratio. The Tier 1 Leverage ratio (T1 LVGR) is the ratio of Tier 1 Capital to total assets. Vlab market leverage ratio $\left(\mathrm{M}-L V G R_{s}\right)$ is the ratio of market cap to quasi-market assets under Vlab stress scenario (eq. (3)). "Min" stands for the minimum ratio across the 9 quarters of the CCAR 2013 scenario. CCAR 2013 ratios do not consider the effect of planned capital actions and are disclosed in the Dodd-Frank Act stress test (DFAST 2013). EBA 2011 ratios are the projected ratios at the end of the stress scenario.

(a) CCAR 2013 min T1 Leverage ratio (wihout the effect of capital actions) vs. Vlab market leverage ratio. Vlab download date: $09 / 28 / 2012$.

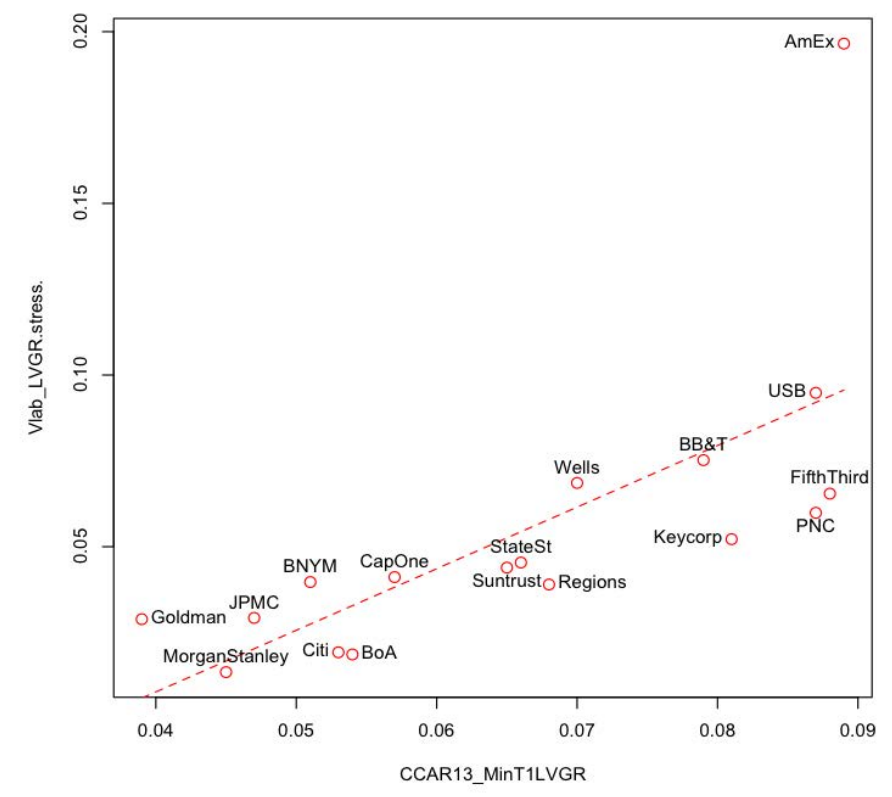

(b) EBA 2011 stressed T1 Leverage ratio vs. Vlab market leverage ratio. Vlab download date: 12/31/2010.

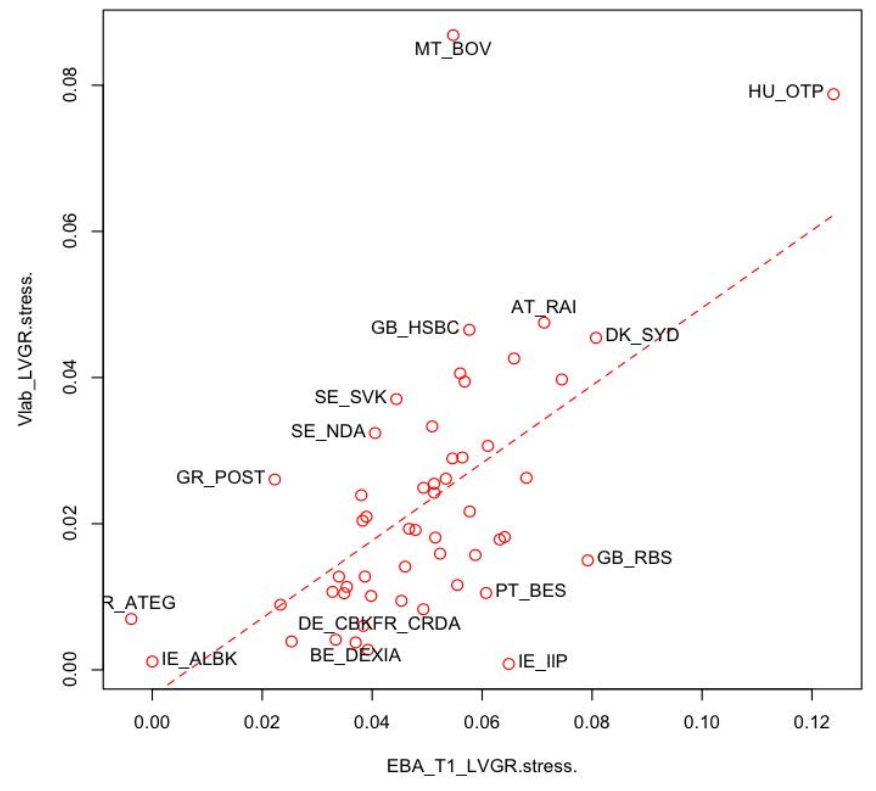




\section{Figure 4: EBA capital shortfalls vs. SRISK}

(a) Disclosed capital shortfall in the EBA 2011 stress test (eq. (4)) vs. SRISK (EUR millions). Vlab download date: 12/31/2010.

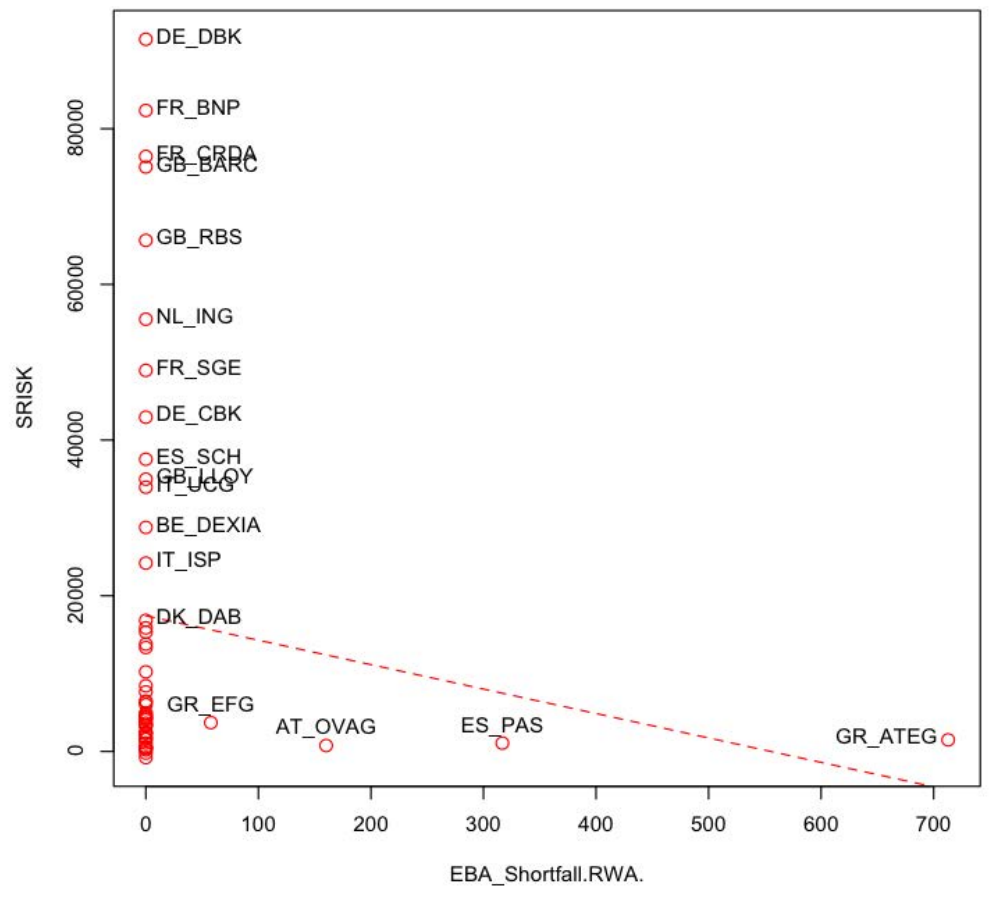

(b) EBA Capital Exercise "Overall Shortfall" (eq. (6)) vs. SRISK (EUR millions). Vlab download date: 09/30/2011.

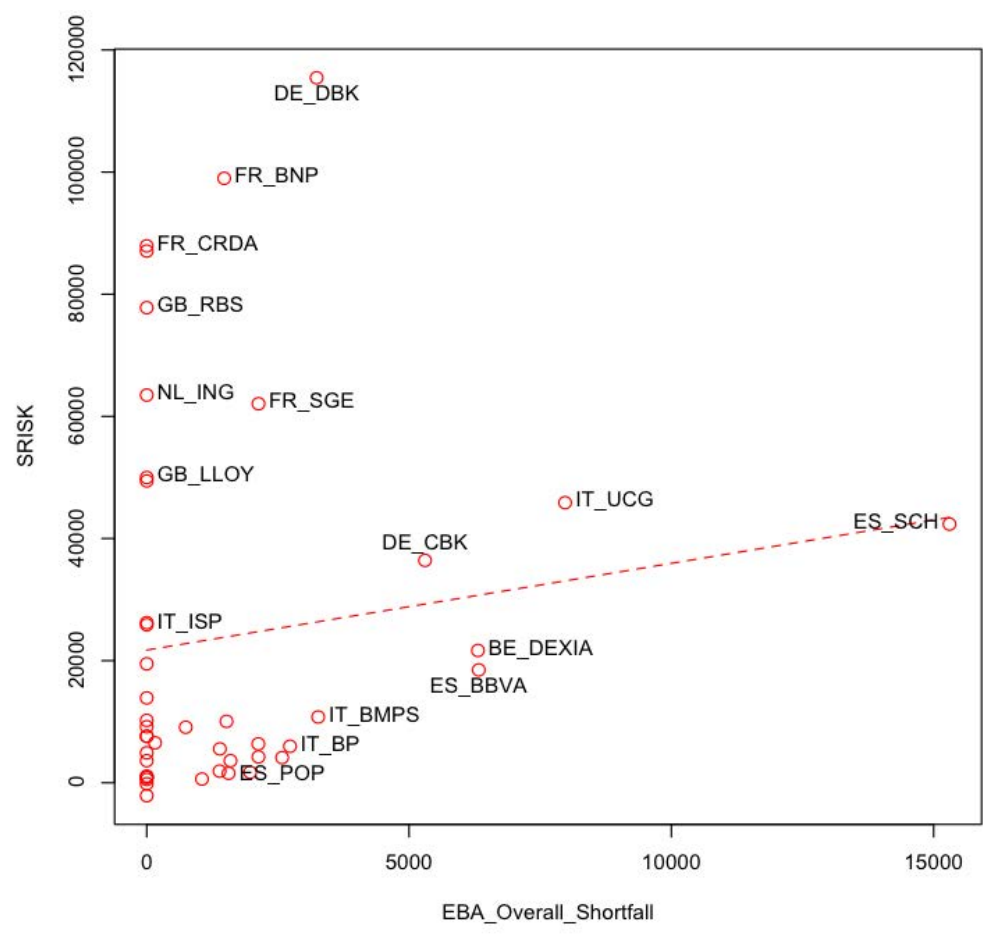


Figure 5: EBA risk-based and leverage-based capital shortfalls vs. SRISK

(a) EBA 2011 stress test 'absolute' risk-based capital shortfall/excess (eq. (5)) vs. SRISK (EUR millions). Vlab download date: $12 / 31 / 2010$.

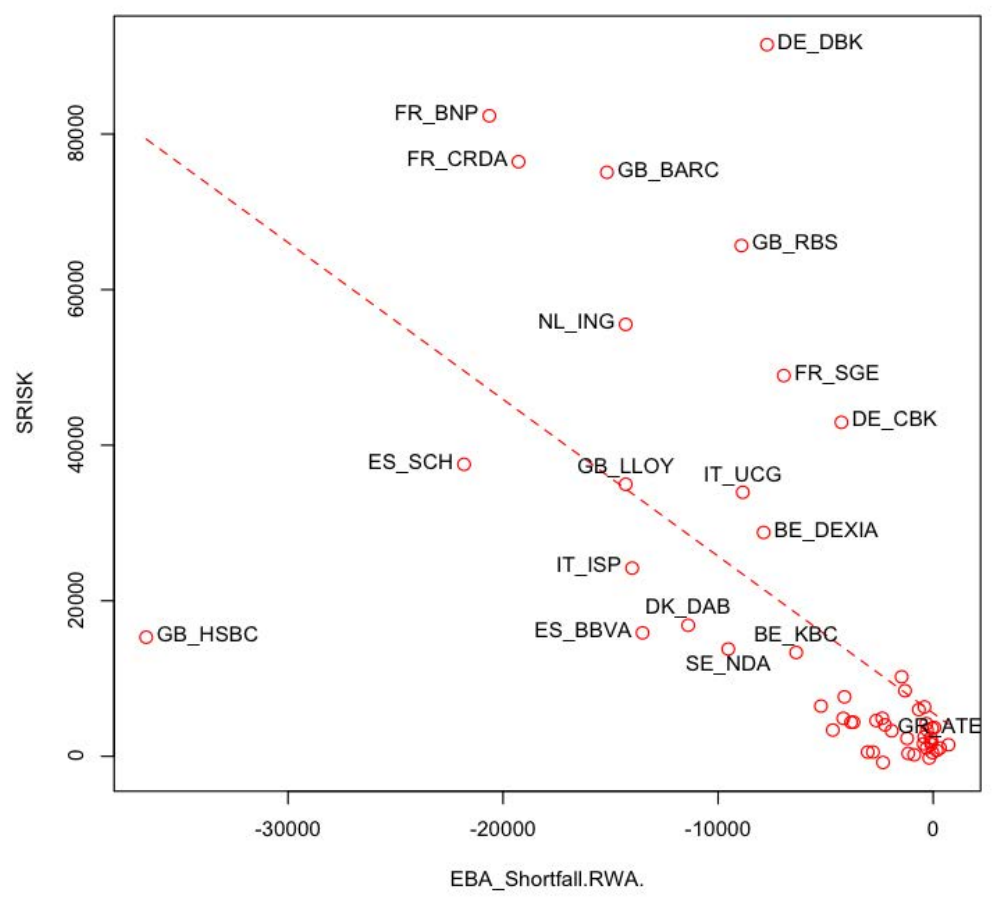

(b) EBA 2011 stress test leverage-based shortfall (eq. (7)) vs. SRISK (EUR millions). Vlab download date: 12/31/2010.

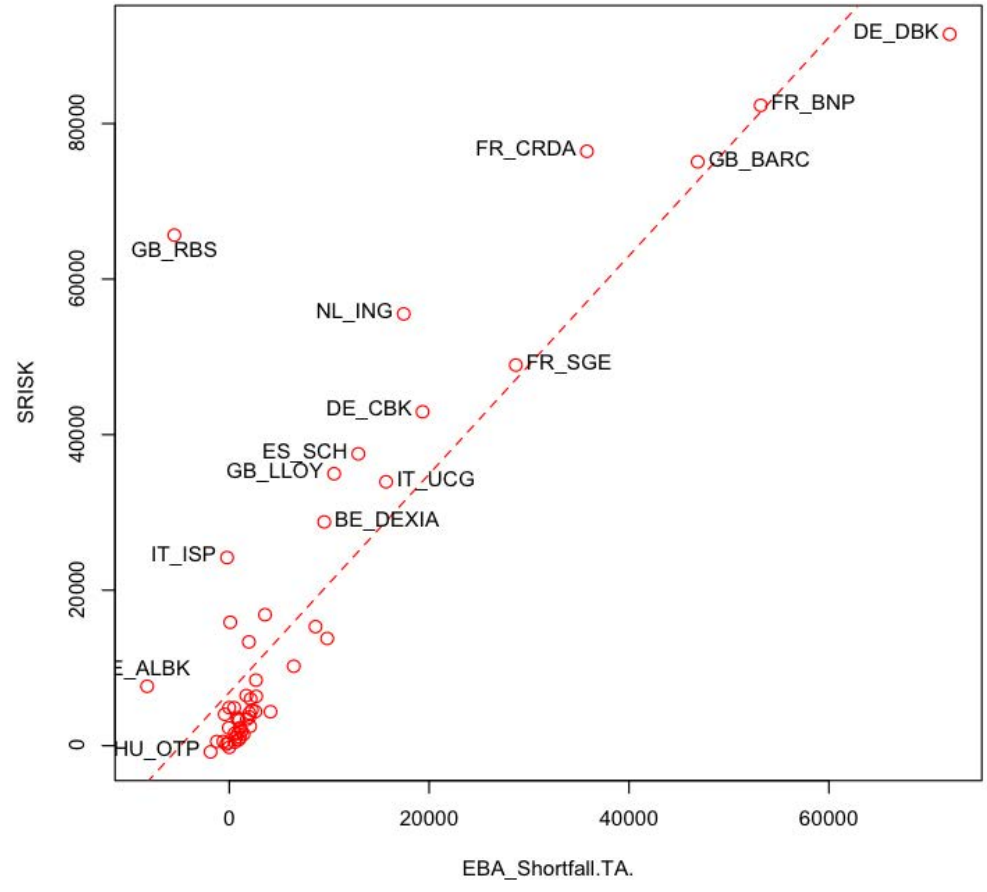


Figure 6: Stress test risk weight vs. Vlab risk weight and T1 leverage ratio. Projected regulatory risk weight at the end of the EBA 2011 stress scenario $\left(\mathrm{RWA}_{S} / \mathrm{TA}_{S}\right.$, horizontal axis) against Vlab risk weight (a), and the projected Tier 1 Leverage ratio at the end of the EBA 2011 stress scenario (b). Vlab download date: 12/31/2010.

(a) Projected regulatory risk weight vs. Vlab risk weight

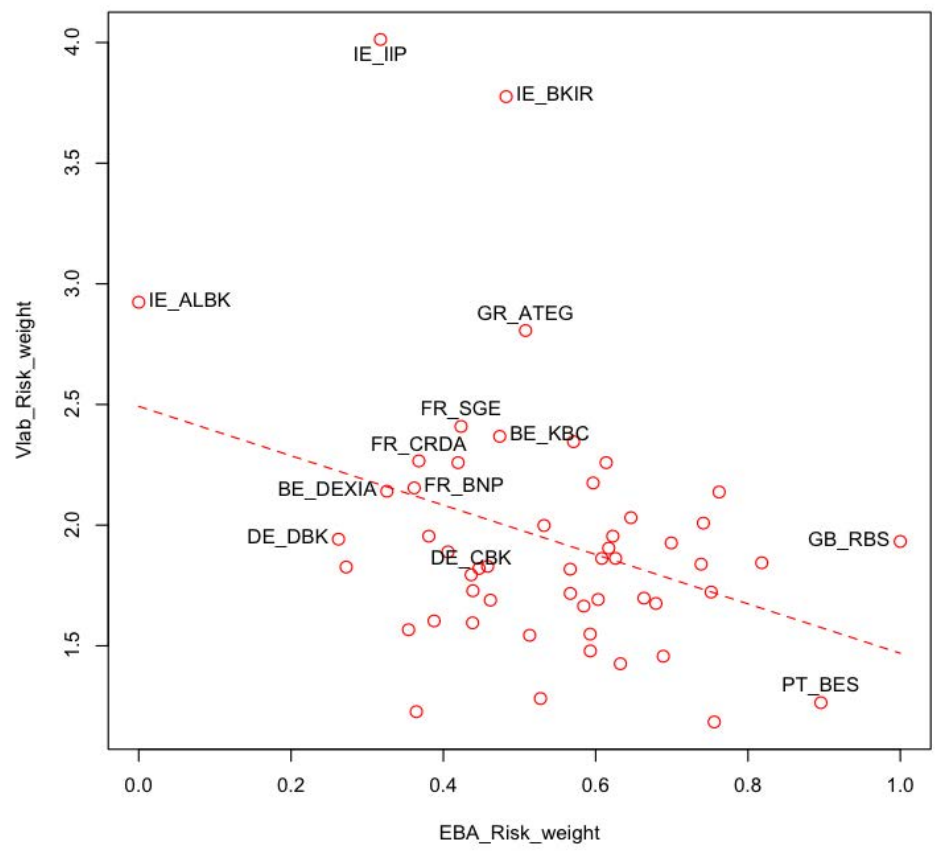

(b) Projected regulatory risk weight vs. projected Tier 1 Leverage ratio at the end of the EBA 2011 stress scenario $\left(\mathrm{T}_{S} / \mathrm{TA}_{S}\right)$

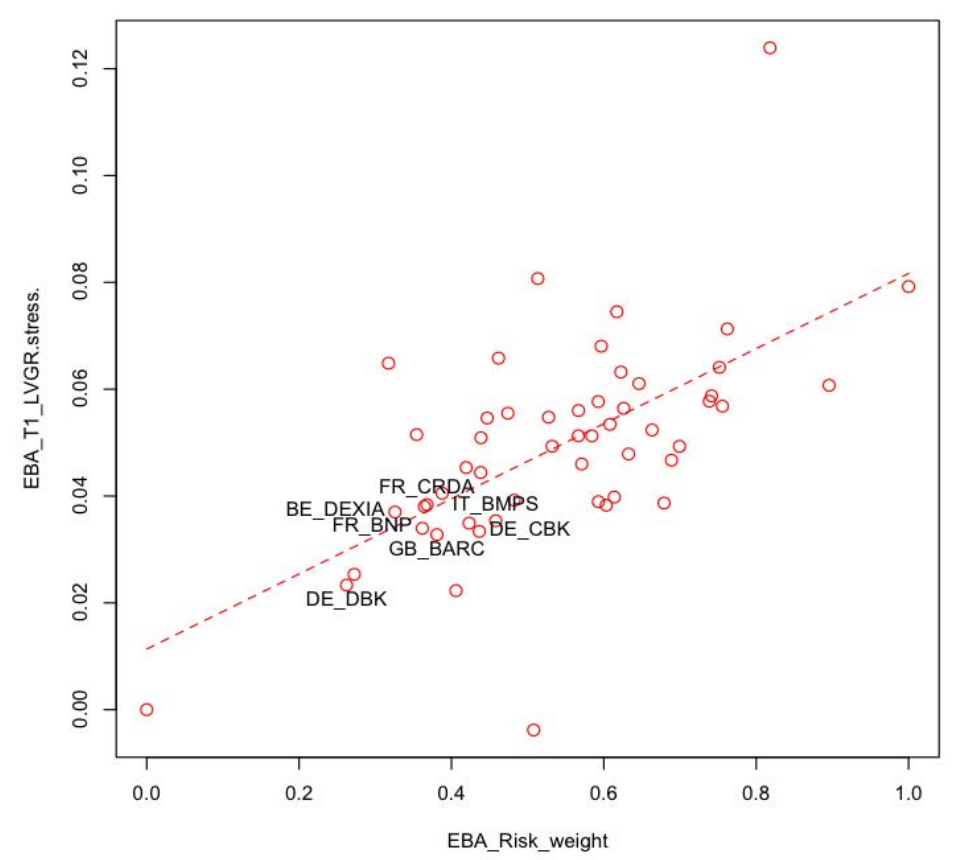




\section{Appendix}

\section{A. Vlab vs. regulatory stress tests design}

\section{A.1. Scenarios}

The design of robust and coherent scenarios has been an important topic of the stress testing literature (Breuer et al. (2009); Flood and Korenko (2013); Glasserman et al. (2012) and others). Stress test results are indeed all conditional on the scenario definition. The scenarios of the Federal Reserve, the EBA and Vlab are different on several dimensions: they consider different variables, horizons, stress levels and trajectories. Vlab scenario is the simplest one; it is a one-factor scenario featuring a $40 \%$ drop in equity prices over six months. Other variables are considered endogenous to the market factor.

The stress scenario of stress tests usually focuses on an adverse macro-economic scenario defined as a deviation from a baseline scenario. The EBA stress scenario developed by the European Central Bank features a macro-economic stress scenario defined as a deviation of the European Commission forecasts. On the opposite, Vlab is an absolute market stress scenario and prevents the procyclical effects of deviation-based scenarios where stress scenarios, and consequent stress tests outcomes, are more severe during bad times. Also, the Vlab scenario horizon of six months is shorter than stress tests scenarios that typically last two years and justifies better the assumption of most stress tests that banks do not react to the stress scenario.

Unlike Vlab, stress tests scenarios are multi-factor scenarios and the principal challenge of the scenario design is coherence. Stresses have to be consistent across the multiple variables such that the joint outcome of the scenario is economically realistic. The challenge of coherence also grows as the number of variables increases. The SCAP 2009 considered only three factors: the real GDP growth, the unemployment rate and house prices. The CCAR 2012 stress scenario defines trajectories for 25 macro-economic and financial variables, and additionally accounts for a global market shock on the six BHCs with large trading activities. The number of factors in the ECB scenario exceeds 70 variables and the ECB also considers a market stress scenario conditional on the macro-economic scenario.

The question of causality of macro-economic variables on financial variables is raised in Alfaro and Drehmann (2009) where severe macro-economic conditions are shown to be subsequent to the beginning of financial crises. This argument questions the whole relevance of macro-economic scenarios and the models used to map macro scenarios on the financial performance of banks. Macro-economic scenarios defined by exogenous shocks on macroeconomic variables are rooted in the microprudential perspective as it ignores the endogenous 
nature of systemic risk where feedback effects from the financial sector amplify the macroeconomic crisis.

The robustness of stress tests scenarios is also questioned. Borio et al. (2012) indicate that the selection of a stress scenario is easier when the stress tests are crisis management tools as they are designed when the key risks are apparent. Indeed, in the SCAP 2009, a decline of local house prices is a significant factor explaining larger loan loss rates. In the EBA 2011, country-specific shocks to sovereign credit spreads are translated into valuation haircuts of banks sovereign exposures.

Other concerns on stress tests come from the focus on the coherence and plausibility of stress scenarios, which could dilute their severity. Comparing to the $40 \%$ equity market index decline over six months of Vlab; the EBA stress scenario considers a fall of between $10 \%$ up to $20 \%$ in equity prices over two years. The CCAR 2012 assumes a $50 \%$ drop in the Dow Jones total stock market index at the middle of the scenario (late 2012) but then reverts at the end of the scenario to a higher level than pre-scenario prices. We argue that this focus on plausibility, while can facilitate the buy-in of all stakeholders involved in a macro stress test (Borio et al. (2012)), severely undermines the reliability of stress tests results.

\section{A.2. Data}

\section{A.2.1. Public vs. supervisory}

US and EU-wide stress tests are implemented using extended bank supervisory data. US BHCs submit their data confidentially to the Federal Reserve using standardized FR Y-14A forms. These forms contain detailed information on capital composition, loans and securities portfolios, trading and counterparty exposures, and historical P\&L. The reports additionally collect BHCs' own projections of loss and revenues and their estimates of exposures sensitivities to a set of risk factors specified by the Federal Reserve. In Europe, banks implement stress tests themselves and use their own data. Banks are encouraged by the EBA to use all the time series available on credit risk parameters and P\&L figures for the application of the macro scenario.

Next to EU and US extensive-data based stress tests, Vlab could be qualified as a noninvasive stress test. Vlab results are obtained from a reduced dataset of publicly available data including historical market prices, market cap and leverage.

\section{A.2.2. Market vs. accounting}

The stress scenario is mostly applied to accounting data in the supervisory stress tests whereas Vlab stresses the market value of equity. In that respect, Vlab can be viewed as a mark-to-market stress test. Market prices are believed to reflect expectations of all market 
participants on banks performance and are available in real time. Harris et al. (2012) further argue that balance sheet data, being single point estimates at a specific reporting date, cannot reflect the dynamic risks embedded in assets and liabilities. For these reasons, market data are considered to be more informative than accounting numbers.

Another problem concerning accounting data comes from their lack of uniformity. Accounting standards are different; US banks report under US GAAPs and European banks under IFRS. This leads to large differences in the leverage ratios as mentioned earlier. But even using the same standards they are still some large cross-border differences as pointed out by the EBA. Moreover, accounting rules are subject to different interpretations at the bank level.

Then, along with its informative content, we can also question the reliability of accounting data during a crisis. We have shown in Section 5.3 that banks with a high book-to-market ratio experienced higher realized volatility during the European sovereign debt crisis. The positive and significant correlation between the book-to-market ratio and risk indicates that investors do not trust banks estimates of their capital levels during a crisis. In the US too, the book-to-market ratio increased after the financial crisis; market capitalizations were far above regulatory capital levels in 2008 but the regulatory capital becomes larger than the market cap for many banks in 2011.

\section{A.3. Vlab as a macroprudential benchmark}

According to Borio et al. (2012), any stress test has four elements: the scenario, the risk exposures (or the bank data), the model and the outcome. The scenario specifies the shocks to be applied to bank data using a specific model, and the resulting measures are the final outcome of the stress test. The simplicity of Vlab on the scenario and data dimensions could represent its main weakness. It does not have the information granularity at the asset category or exposure level that stress tests have. Vlab does not however do worse than stress tests when it comes to forecasting real bank outcomes during a crisis as shown in Section 3.2. Instead, the use of publicly available market data makes Vlab estimates richer and more transparent; it provides real-time forward looking measures of risk and the use of market data also addresses the concerns on the reliability and consistency of accountingbased measurement across firms. The simplicity of the Vlab scenario makes its outcomes robust to various economic environments and supports the argument in Haldane (2011, 2012) that complex uncertain environments call for simpler rules. Vlab severity makes SRISK the binding constraint for banks where stress tests estimates are not (Hanson et al. (2011)), and requiring banks to raise SRISK is likely to bring the benefits of greater stability 
to the financial system. Vlab SRISK is therefore viewed as a macroprudential benchmark addressing the concerns on the lack of robustness, severity and transparency of stress tests measures, that regulators may be interested to use in the assessment of their own stress tests outcomes. 


\section{B. Supplementary figures}

Figure B.1: EBA 2011 capital ratios vs. Vlab market leverage ratio. The Core Tier 1 capital ratio is the ratio of Core Tier 1 Capital to risk-weighted assets at the end of the stress scenario (December 2012). Banks pass the stress test if their stressed T1CR is larger than 5\%. The Tier 1 Leverage capital ratio is the ratio of Tier 1 Capital to total assets at the end of the stress scenario. Vlab M-LVGR $s$ is the ratio of market cap to quasi-market assets under Vlab stress scenario (eq. (3)). Vlab download date: $12 / 31 / 2010$. Banks are ranked according to their stress test capital ratios.

(a) Core Tier 1 capital ratio of large banks at the end of the EBA 2011 stress scenario (blue, threshold 5\%) vs. Vlab market leverage ratio (M-LVGR under stress) (red).

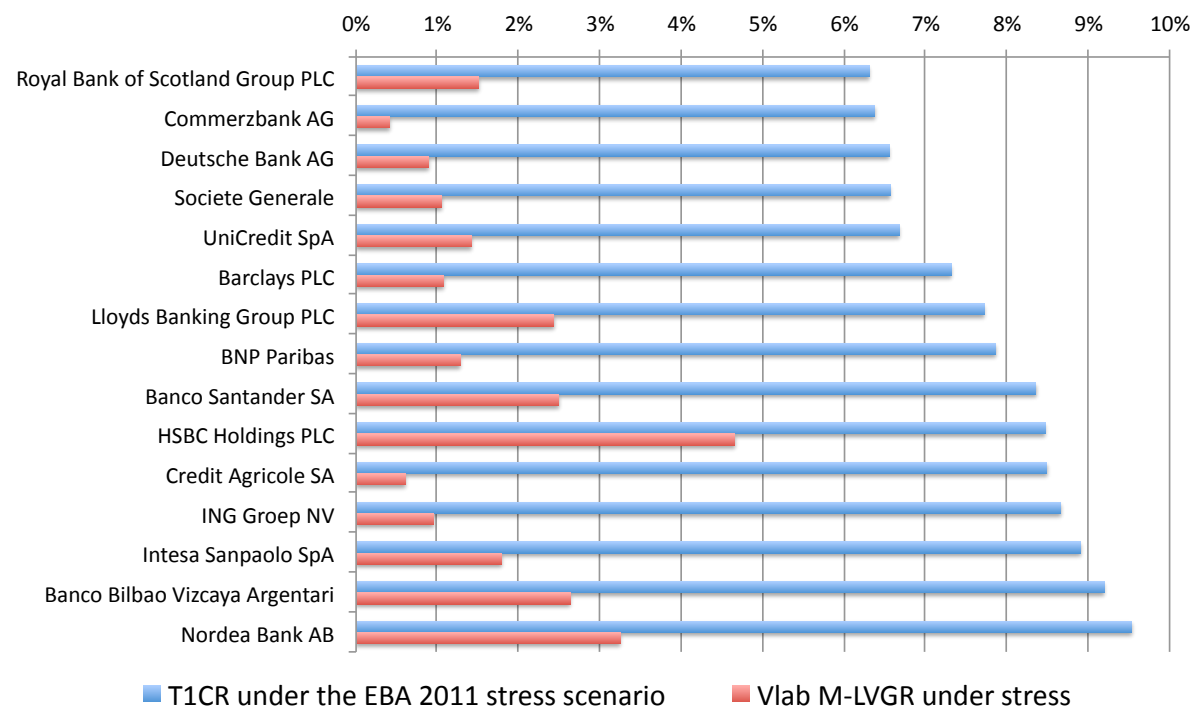

(b) Tier 1 Leverage ratio (T1 LVGR) at the end of the EBA 2011 stress scenario (blue) vs. Vlab market leverage ratio (M-LVGR under stress) (red).

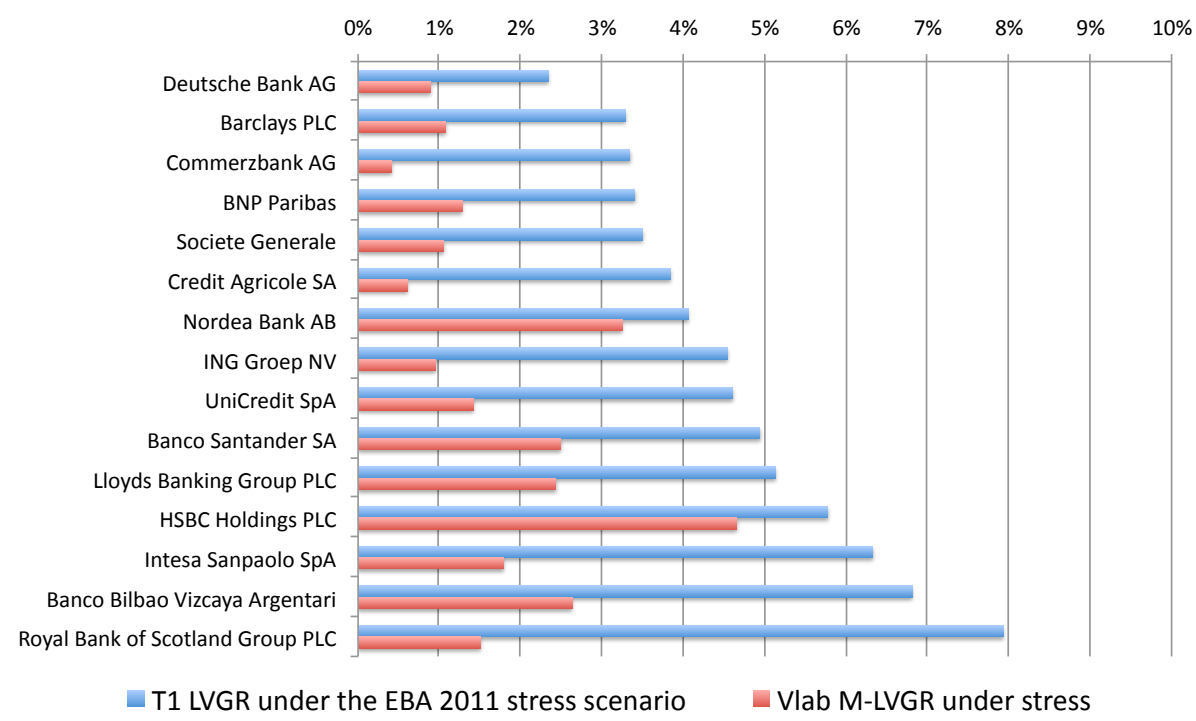


Figure B.2: CCAR 2012 capital ratios vs. Vlab market leverage ratio. The Tier 1 Common capital ratio (T1CR) is the ratio of Tier 1 Common Capital to risk-weighted assets. The Tier 1 Leverage ratio (T1 LVGR) is the ratio of Tier 1 Capital to total assets. "Min" stands for the minimum ratio across the 9 quarters of the CCAR 2012 scenario (Q4 2011 to Q4 2013). Note that the different minimum ratios of banks may not happen during the same quarter. CCAR 2012 ratios do not consider the effect of planned capital actions. Thresholds to pass the stress test (min ratios have to be larger than): 5\% (Min T1CR), 3-4\% (Min T1 LVGR). Banks with a 4\% T1 LVGR threshold: Ally, American Express, Capital One and MetLife. Vlab M-LVGR is the ratio of market cap to quasi-market assets under Vlab stress scenario (eq. (3)). Vlab download date: 09/30/2011. Banks are ranked according to their stress test capital ratios.

(a) Min Tier 1 Common capital ratio (Min T1CR) under the CCAR 2012 stress scenario (blue, threshold 5\%) vs. Vlab market leverage ratio (M-LVGR under stress) (red).

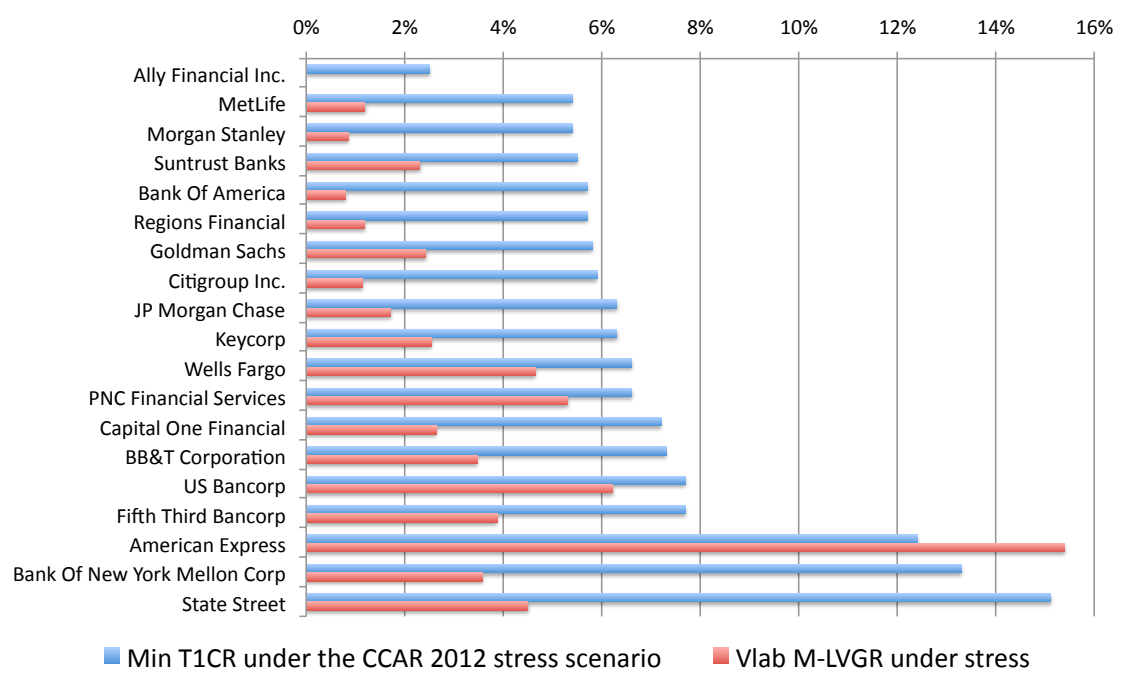

(b) Min Tier 1 Leverage ratio (Min T1 LVGR) under the CCAR 2012 stress scenario (blue, threshold 3-4\%) vs. Vlab market leverage ratio (M-LVGR under stress) (red).

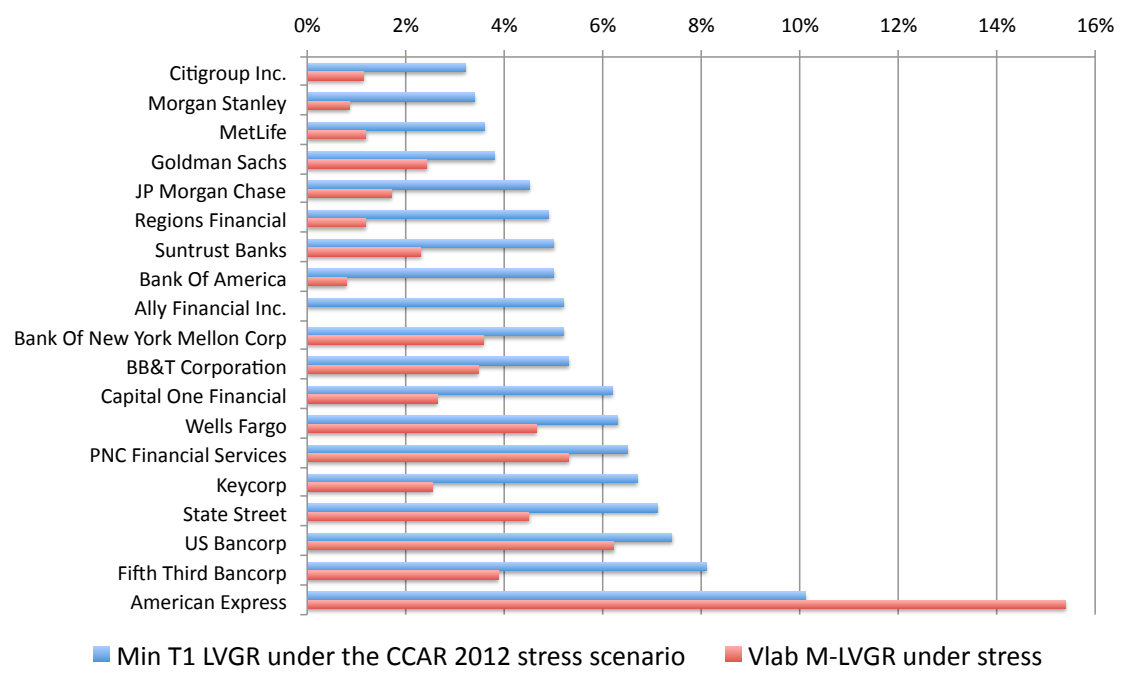


Figure B.3: CCAR 2013 capital ratios vs. Vlab market leverage ratio. The Tier 1 Common capital ratio (T1CR) is the ratio of Tier 1 Common Capital to risk-weighted assets. The Tier 1 Leverage ratio (T1 LVGR) is the ratio of Tier 1 Capital to total assets. "Min" stands for the minimum ratio across the 9 quarters of the CCAR 2013 scenario (Q4 2012 to Q4 2014). Note that the different minimum ratios of banks may not happen during the same quarter. CCAR 2013 ratios do not consider the effect of planned capital actions and are disclosed in the Dodd-Frank Act stress test (DFAST 2013). Thresholds to pass the stress test (min ratios have to be larger than): 5\% (Min T1CR), 3-4\% (Min T1 LVGR). Banks with a 4\% T1 LVGR threshold: Ally, American Express and Capital One. Vlab M-LVGR $s$ is the ratio of market cap to quasi-market assets under Vlab stress scenario (eq. (3)). Vlab download date: 09/28/2012. Banks are ranked according to their stress test capital ratios.

(a) Min Tier 1 Common capital ratio (Min T1CR) under the CCAR 2013 stress scenario (blue, threshold 5\%) vs. Vlab market leverage ratio (M-LVGR under stress) (red).

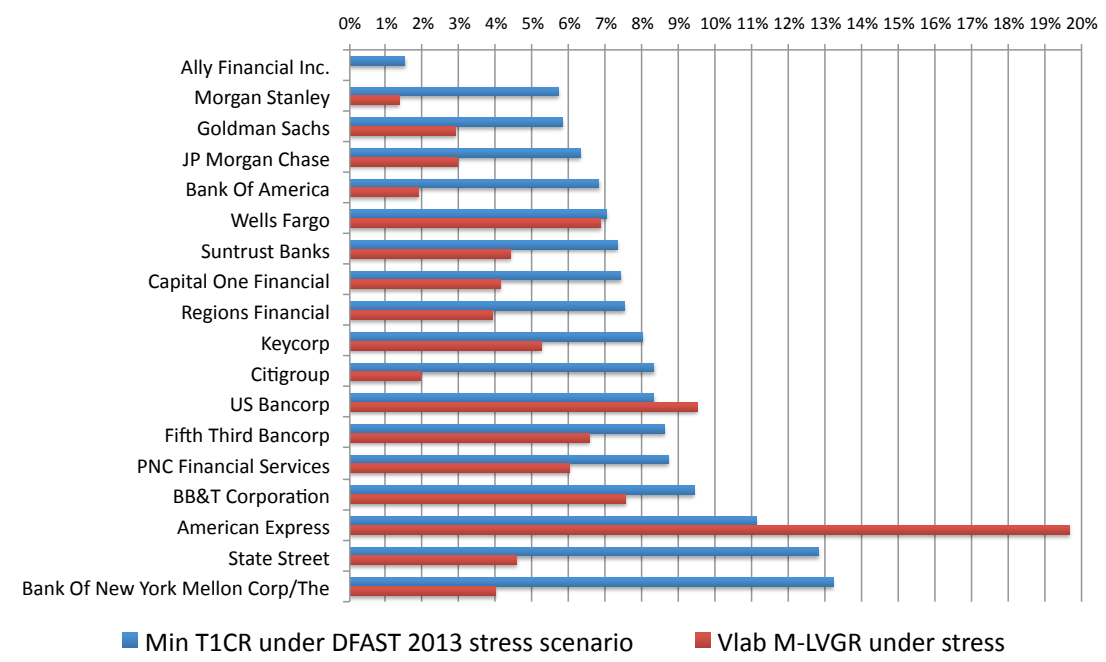

(b) Min Tier 1 Leverage ratio (Min T1 LVGR) under the CCAR 2013 stress scenario (blue, threshold 3-4\%) vs. Vlab market leverage ratio (M-LVGR under stress) (red).

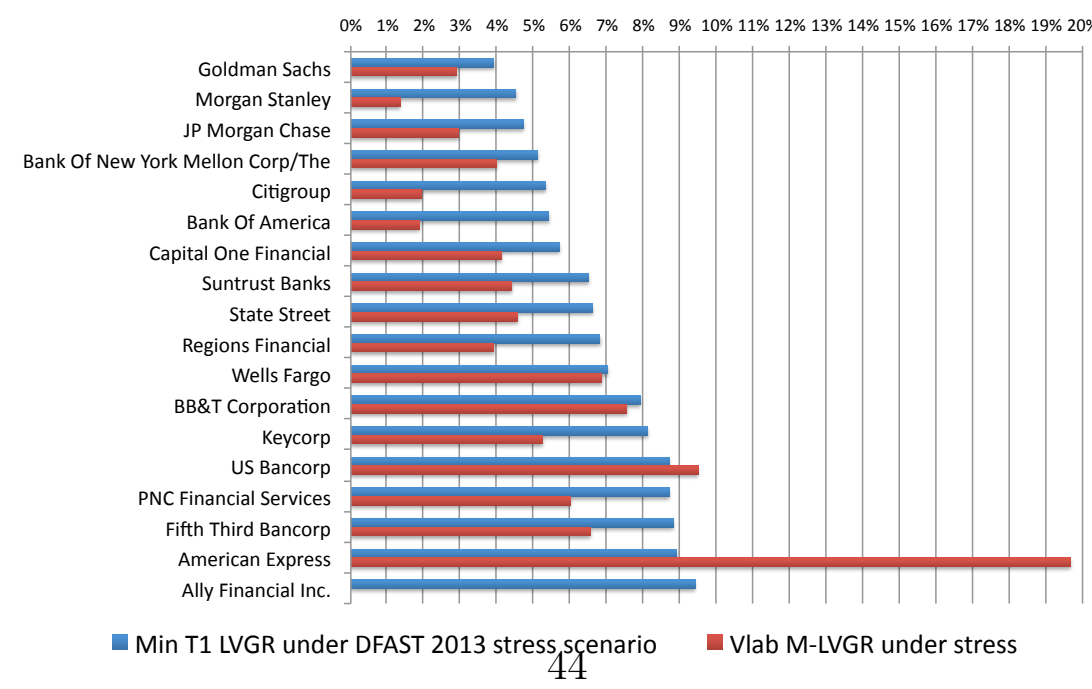

